\title{
Modelling guidelines for Core Exit Temperature simulations with system codes
}

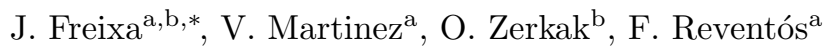 \\ ${ }^{a}$ Department of Physics and Nuclear Engineering, Technical University of Catalonia (UPC), Spain \\ ${ }^{b}$ Paul Scherrer Institut (PSI), 5232 Villigen PSI, Switzerland
}

\begin{abstract}
Core exit temperature (CET) measurements play an important role in the sequence of actions under accidental conditions in pressurized water reactors (PWR). Given the difficulties in placing measurements in the core region, CET readings are used as criterion for the initiation of accident management (AM) procedures because they can indicate a core heat up scenario. However, the CET responses have some limitation in detecting inadequate core cooling and core uncovery simply because the measurement is not placed inside the core. Therefore, it is of main importance in the field of nuclear safety for PWR power plants to assess the capabilities of system codes for simulating the relation between the CET and the peak cladding temperature $(\mathrm{PCT})$.

The work presented in this paper intends to address this open question by making use of experimental work at integral test facilities (ITF) where experiments related to the evolution of the CET and the PCT during transient conditions have been carried out. In particular, simulations of two experiments performed at the ROSA/LSTF and PKL facilities are presented. The two experiments are part of a counterpart exercise between the OECD/NEA ROSA-2 and OECD/NEA PKL-2 projects.

The simulations are used to derive guidelines in how to correctly reproduce the CET response during a core heat up scenario. Three aspects have been identified to be of main importance: (1) the need for a 3 -dimensional representation of the core and Upper Plenum (UP) regions in order to model the heterogeneity of the power zones and axial areas, (2) the detailed representation of the active and passive heat structures, and (3) the use of simulated thermocouples instead of steam temperatures to represent the CET readings.
\end{abstract}

Keywords: PWR, CET, SAMG, heat transfer

\section{Introduction}

Core exit temperature (CET) measurements play an important role in the sequence of actions under accidental conditions in pressurized water reactors (PWR). Given the difficulties in placing measurements in the core region, CET readings are used as criterion for the initiation of accident management (AM) procedures because they can indicate a core heat up scenario. Within the OECD countries, the CET readings are used in: Emergency Operation Procedures (EOP) as a prevention of AM, the transition from EOP to Severe Accident Management Guidelines (SAMG), in SAMG (mitigation AM) and, in some cases, in emergency planning (Tóth et al., 2010). However, the CET responses may present some limitations in detecting inadequate core cooling and core uncovery since the corresponding thermocouples (TC) cannot be placed directly inside the core cavity for technical and operational reasons. Therefore, differences between the CET and the peak cladding temperature (PCT) are expected. In fact, whenever the CET indicates the

\footnotetext{
*Corresponding author. Tel.: +34-934017454.

Email addresses: jordi.freixa-terradas@upc.edu (J. Freixa), victor.martinez@nortuen.com (V. Martinez), omar.zerkak@psi.ch (O. Zerkak), francesc.reventos@upc.edu (F. Reventós)
} 
presence of superheated steam it is always with certain delay and the steam temperature at the location of the TC will be always lower than the actual maximum cladding temperature in the core. Therefore, core uncovery will be unnoticed during a certain period of time. Considering these known limitations, it is important for the safety of the PWRs, and in particular for the design of EOPs and SAMGs, to assess the capabilities of system codes to simulate the relation between the CET and the PCT under accidental conditions.

Experimental results obtained at the Large Scale Test Facility (LSTF) within the OECD/NEA ROSA-1 project (Suzuki et al., 2009) suggested that the response of the CET thermocouples could be inadequate to initiate the relevant AM actions. In particular, during Test 6-1 (Takeda et al., 2006), a small break lossof-coolant-accident (SBLOCA), it was observed that core uncovery started well before CET thermocouples reported sufficient high temperatures (Takeda et al., 2007). In order to address this issue, the Committee on the Safety of Nuclear Installations (CSNI) launched activities to review the current state of knowledge on the CET performance and related AM procedures. As a result, the CSNI delivered a report in 2010 with conclusions and recommendations on the issue (Tóth et al., 2010). The CSNI concluded that current thermal-hydraulic system codes used to model and analyze the CET performance may not be sufficiently validated and recommended to verify to what extent state-of-the-art system codes are able to reproduce the delay and differences between rod surface temperatures and CET readings. The CSNI report concluded that further research should be dedicated, among others, at the following activities:

- Assessment of physical models to predict heat transfer modes affecting CET behavior

- Development of a "best practice guidelines" for the nodalization approach of the uncovered core section up to the point of CET location

- Based on comparison results, assessment of the possible impact of 3-D effects not modelled in these codes

- Investigate the problem of CETs issue "scaling" (methods of extrapolating) from experimental facilities size, like LSTF, to commercial PWR reactors

The work presented in this paper intends to address these open questions by making use of experimental work at integral test facilities (ITF) where experiments related to the evolution of the CET and the PCT during transient conditions have been carried out. Actually, following the recommendations of the CSNI report, a link between two OECD/NEA projects (the ROSA-2 and the PKL-2 projects) was established with the intention to carry out a counterpart experiment. Both the OECD/NEA ROSA-2 and the OECD/NEA PKL-2 projects aimed to resolve key light water reactor thermal-hydraulics safety issues. The former consisted of experiments at the ROSA/LSTF operated by the Japan Atomic Energy Agency (JAEA) while the latter was based on experiments at the Primärkreislauf-Versuchsanlage (primary coolant loop test facility) PKL operated by AREVA NP. In particular, Test 3 of the OECD/NEA ROSA-2 project and Test G7.1 of the PKL facility were designed as counterpart experiments with the aim of studying the evolution of the CET in comparison to the PCT.

The counterpart experiments represented a hot leg SBLOCA scenario with additional system failures, namely: total failure of the high pressure safety injection (HPSI) system combined with no secondary side anticipated cool down. In this scenario, AM measures are essential to prevent unacceptable core heat-up. In the experiment, a secondary depressurization is employed as AM measure to restore the heat sink through fast reduction of the primary pressure leading to a passive Accumulators (Acc) injection and followed by the low pressure safety injection (LPSI). The AM is initiated by the observance of a high CET.

In addition to the differences in geometry, scale and design between the two facilities, the PKL facility has a maximum allowed primary side pressure of 50 bars while the ROSA/LSTF facility operates at full pressure of a PWR (160 bars). This limitation further complicated the definition of the counterpart boundary conditions as this will be explained in Section 2 with more details. 


\subsection{Phenomenology}

During a core heat up scenario, the fuel rod cladding temperature increases above the saturation temperature due to insufficient core cooling. Some of the excess heat is transferred from the rod surface to the surrounding fluid. The fluid continiously flow upwards by means of convection to the CET located above the Upper Core Plate (UCP). In its way to the upper plenum (UP) plenum the fluid has a continuos heat exchange to the metal structures (both heated and unheated). Heat is finally delivered to the CET sensor, when the fluid reaches the UP. As a result, there will always be a time delay between the PCT occurrance and its detection at the CET thermocouple. Another important aspect to consider in the process is the thermal inertia of the internals which leads to a non-stationary heat transfer configuration between the core cavity and the UP. Therefore, the temperature reading at the CET location will not only be delayed but also dampened in comparison to the actual PCT.

Experimental studies have been carried out to assess the performance of CET measurements for PWRs in several ITFs. Of particular interest is the review presented by Tóth et al. (2010) where results obtained at the LOFT, PKL, ROSA/LSTF and PSB test facilities are summarized. The experimental work served to analyze the phenomenology associated with the CET response to a core heat up scenario. The different studies were conducted independently but reached similar conclusions on the physical phenomena that influence the evolution of the CET as a function of the maximum cladding temperature in the core. The study is used in this work to identify what are the needs for the correct simulation of a scenario where CET response play an important role:

- The steam velocity distribution throughout the core cavity, which will depend on the break size and location but also on the radial and axial details, the different pass-through areas throughout the core and UP regions.

- The relatively weak heat transfer from the rod surface to the surrounding steam due to low steam velocities during boil-off.

- Inside and above the core, the axial and radial core power profile and, to a lower extent, the effects of core barrel and heat losses.

- Cooling effect of the unheated structures in the upper part of the core cavity and above.

- Mixing effects in the core and UP due to internals, grid spacers and nonuniform radial power distribution.

- Water backflow from the hot legs during core heat up due to steam condensation in the Steam Generator (SG) tubes, pressurizer water fall down or water from hot leg ECC injection. These two phenomena may lead to wetted or unwetted thermocouples.

One additional physical phenomenon not listed in the above mentioned reference but that could influence the measurements above the upper core plate is thermal radiation from the fuel rods which can be significant during the core heat up phase when fuel rod temperature may reach up to $1000 \mathrm{~K}$.

In order to adequately capture all these phenomena, a detailed reproduction of the passive and active heat structures must be provided. In addition, radial power and the steam velocities distribution should be reproduced. Details on how to model these aspects with system codes are given in Section 4.

\section{The OECD/NEA ROSA-2 and PKL-2 counterpart experiment}

Following an agreement between the OECD/NEA ROSA-2 and PKL-2 projects two similar experiments were conducted at the ROSA/LSTF and PKL test facilities, respectively, to result in a set of counterpart experiments for the simulation at different scales and pressures of the same accidental configurations leading to core heat up and reflooding sequences.

ROSA/LSTF is an experimental facility operated by JAEA, it is designed to simulate a Westinghousetype 4-loop 3,420 MWth PWR under accidental conditions (The ROSA-V Group, 2003). It is a full-height 
and 1/48 volumetrically-scaled two-loop system with a maximum core power of $10 \mathrm{MW}$ (14\% of the scaled PWR nominal core power) and pressures scaled 1:1. Loops are sized to conserve volumetric factor $(2 / 48)$ and to simulate the same flow regime transitions in the horizontal legs (preserving $L / \sqrt{(} D)$ factor). The core power is distributed over 20 fuel assemblies with 3 different power peaking factors, all assemblies have the same cosine-shaped axial power distribution.

PKL is an ITF that reproduces the entire primary system and most of the secondary system (except for the turbine and condenser) of a 1300-MW PWR plant operated by AREVA (Kremin et al., 2001). It is based on a 4-loop Siemens design (KWU), with elevations scaled 1:1 and volumes and power reduced by a factor of 145 . The number of rods in the core and the U-tubes in the steam generator has been divided by 145 as well, following the power to volume scaling criterion. The core is modeled by 314 electrical heater rods with a flat axial power profile and homogeneous radial distribution. PKL simulates all four loops separately. The operating pressure of the PKL facility is limited to 45 bars on the primary side and to 56 bars on the secondary side. This nevertheless allows simulation over a wide temperature range (522K to $322 \mathrm{~K})$, while requiring test procedure adaptations to address the high-pressure initial phase of typical PWR SBLOCA sequences.

In addition to the differences in geometry, scale and design between the two facilities the difference in the maximum allowed primary pressure between the two facilities further complicates the definition of the counterpart boundary conditions because the core uncovery and increase of the CET typically occur in the range of pressures from 60 to 80 bars. In order to model the event at the intended pressure and perform a counterpart experiment with the PKL facility, Test 3 of the OECD/NEA ROSA-2 project was divided in three phases: a high pressure transient as it would occur in a normal PWR, a conditioning phase to bring the facility to a pseudo-steady state at around 50 bars, and a low pressure transient where the same transient is reproduced once again at a lower pressure corresponding to the operational pressure of the PKL facility. In turn, the initial conditions of the PKL facility were set to the same conditions as those of the ROSA-2 Test 3 low pressure phase.

\subsection{ROSA-2 Test 3}

The boundary conditions of the counterpart experiment are shown in Table 1, the high pressure transient was only performed in the ROSA/LSTF facility while the low pressure transient was carried out in both test facilities. The test is initiated by opening a valve located in the upper side of the hot leg with a throat opening of $1.5 \%$ of the cold leg area (Takeda et al., 2012). At the same time, loss of offsite power is assumed thus leading to the shut down of the primary pumps and the unavailability of the HPSI and the main feedwater system. Due to the loss of coolant, a steep depressurization of the primary system takes place and the SCRAM signal is reached. As a consequence, the main steam isolation valves are closed causing an increase of the secondary pressure. The set-points for the opening of the secondary side relief valves are soon reached and the secondary pressure oscillates around these setpoints following the intermittent openings and closings of the valve. Since HPSI is unavailable, the primary system is continuously loosing coolant. When the coolant level in the system decreases below the hot leg connection to the UP, the break flow turns into single phase steam flow. In this case the primary system pressure will decrease below the secondary pressure and core boil off will initiate. An increase of the cladding temperature and the CET will follows thereafter.

A conditioning phase is carried out after the high pressure transient to bring the system to a stable reflux condensation state at around 45 bars and a reduced primary coolant inventory equivalent to the initial conditions of the PKL Test G7.1. The main steam relief valve set-points are modified to bring the system towards these conditions. When the system is stabilized, the break valve is opened again and the low pressure transient begins. Further actions during this phase are (the same actions are performed in the PKL Test G7.1):

- Initiation of SG secondary-side depressurization by fully opening the relief valves, and initiation of the auxiliary feedwater (AFW) system in both loops as AM action. These actions are performed when the maximum core exit temperature reaches $623 \mathrm{~K}$.

- Initiation of Acc injection when the primary pressure reaches 26 bars. 
- Initiation of the LPSI when the pressure in the lower plenum of the Reactor Pressure Vessel (RPV) reaches 10 bars.

\begin{tabular}{|c|c|}
\hline Event & condition \\
\hline \multicolumn{2}{|c|}{ High pressure transient } \\
\hline Break opens & Time zero \\
\hline Generation of scram signal & Primary pressure = $12.97 \mathrm{MPa}$. \\
\hline PZR heater off & $\begin{array}{l}\text { Generation of scram signal or PZR liq- } \\
\text { uid level below } 2.3 \mathrm{~m}\end{array}$ \\
\hline $\begin{array}{l}\text { Initiation of core power decay curve simulation } \\
\text { Initiation of primary coolant pump coastdown } \\
\text { Turbine trip (closure of stop valve) } \\
\text { Closure of main steam isolation valve } \\
\text { Termination of main feedwater }\end{array}$ & Generation of scram signal \\
\hline Opening and closing of the SG relief valves & $\begin{array}{l}\text { SG secondary-side pressure }=8.03 / 7.82 \\
\mathrm{MPa}\end{array}$ \\
\hline Generation of SI signal & Primary pressure $=12.27 \mathrm{MPa}$ \\
\hline $\begin{array}{l}\text { Initiation of HPI coolant injection into RPV upper } \\
\text { plenum }\end{array}$ & $\begin{array}{l}\text { Maximum fuel rod surface temperature } \\
=750 \mathrm{~K}\end{array}$ \\
\hline \multicolumn{2}{|c|}{ Low pressure transient } \\
\hline Break opens & Low pressure transient initiates \\
\hline $\begin{array}{l}\text { Initiation of SG secondary-side depressurization by } \\
\text { fully opening SGRVs as AM action }\end{array}$ & $\begin{array}{l}\text { Maximum core exit temperature }=623 \\
\mathrm{~K}\end{array}$ \\
\hline Initiation of $\mathrm{AFW}$ in both loops & initiation of AM action \\
\hline Initiation of accumulator system & Primary pressure $=2.6 \mathrm{MPa}$ \\
\hline Initiation of low pressure injection system & $\mathrm{PV}$ lower plenum pressure $=1.0 \mathrm{MPa}$ \\
\hline
\end{tabular}

Table 1: Control logic of the counterpart experiment Takeda et al. (2012)

\subsection{PKL Test G\%.1}

PKL G7.1 counterpart test reproduces the same conditions as in the OECD/NEA ROSA-2 Test 3 (Schoen et al., 2012). The experiment starts with a filled primary system and nominal steady state conditions. A conditioning phase is performed to reduce the primary mass inventory and bring the facility to reflux condensation conditions at around 45 bars. The initial test conditions are reached after secondary side pressurization. The primary level collapsed down to mixture state condition at SG chambers by temporarily opening the break until the primary side mass inventory reaches $40 \%$. The fill level of the SGs secondary side is brought from $12 \mathrm{~m}$ down to $8 \mathrm{~m}$ for consistency with the ROSA/LSTF facility. The obtained steady state conditions represent the PKL G7.1 counterpart of the ROSA/LSTF test conditions prior and correspond to stable reflux condensation conditions.

The low pressure transient is started by opening the break simulator located on the hot leg. Since the break is small, the reflux condensation conditions are maintained and the system pressure does not decrease. 
The system however continuously losses coolant due to the unavailability of the HPSI. The primary system pressure starts falling when the break flow turns into single phase vapor because the energy released through the break becomes larger than the one generated in the core, in the same manner as it occurred in the high pressure transient. This leads to the boil off of the core coolant and the subsequent core uncovery and CET increase.

\section{Simulation of the system behaviour of the counterpart experiment}

The OECD/NEA ROSA-2 Test 3 has been simulated by making use of two distinct thermal-hydraulic codes TRACE and RELAP5Mod3.3, both developed by the United States Nuclear Regulatory Commission (US-NRC) while, PKL Test G7.1 has been carried out only with the RELAP5Mod3.3 code. The TRACE version used is TRACE V5.0 provided with in-house modifications to the choked flow model under single phase steam conditions.

In the following sub-sections the nodalization and the results in terms of system behaviour are described. Detailed explanations on the system code capabilities and modelling approaches related to the physical phenomena listed in Section 1.1 will be provided in Section 4.

\subsection{The ROSA/LSTF TRACE nodalization}

The TRACE model of the LSTF has been developed by the Paul Scherrer Institut and has been validated over the simulation of several ROSA/LSTF tests (Freixa and Manera, 2012, 2010; Freixa et al., 2013a). The model (Figure 1) consists of a 3-Dimensional vessel component, two separate loops with two steam generators and a pressurizer. The 3-D vessel component is composed of 22 axial levels, 4 radial rings and 4 azimuthal sectors. The three inner rings cover the core region and the fourth ring represents the vessel Downcomer (DC). The heater rods are simulated by means of 12 heat structures, one per sector in the radial plane. The rods are grouped in three categories according to the power regions of the LSTF. 8 pipes were used to represent the 8 control rod guide tubes (CRGTs). Details of specific modelling of the break and other code options are listed in Table 2. Further details on the simulation of Test 3 with this nodalization were given by Freixa et al. (2013b).

\subsection{The ROSA/LSTF RELAP5 nodalization}

The ROSA/LSTF RELAP5 nodalization has been previously qualified for the OECD/NEA ROSA-1 Tests 3.13 .2 (Martinez-Quiroga et al., 2012a,b). The full model nodalization used in the present work is shown in Figure 2. The core and upper plenum regions were updated in order to better reproduce the radial power distribution in the core and other phenomena important for Test 3 of the ROSA/LSTF rig. The core region is simulated by 13 parallel channels with 20 axial nodes (the last two cells represent the region around the UCP). The 13 channels correspond to fuel assemblies or groups of fuel assemblies having the same power. Cartesian crossflows were used to distribute them radially. The 8 CRGTs were modelled with 8 distinct pipes connected to the corresponding channel at the bottom and all connected to the same volume that represents the Upper Head (UH). These modifications were reported in detail by Martinez-Quiroga et al. (2014). Details of specific modelling of the break and other code options are listed in Table 2.

\subsection{The PKL RELAP5 nodalization}

The simulation of the PKL Test G7.1 experiment were conducted on a qualified RELAP5 nodalization (Freixa et al., 2009). The core and upper plenum regions were renodalized with three parallel channels (Martinez-Quiroga et al., 2014).

The PKL and ROSA/LSTF RELAP5 nodalizations have been cross-compared using a scaling methodology presented by Martinez-Quiroga and Reventos (2014). The methodology was applied to the counterpart experiment by (Martinez-Quiroga et al., 2014), thus demonstrating the equivalence of both nodalizations in the reproduction of the thermal-hydraulics phenomenology during this transient. Details of specific modelling of the break and other code options are listed in Table 2. 


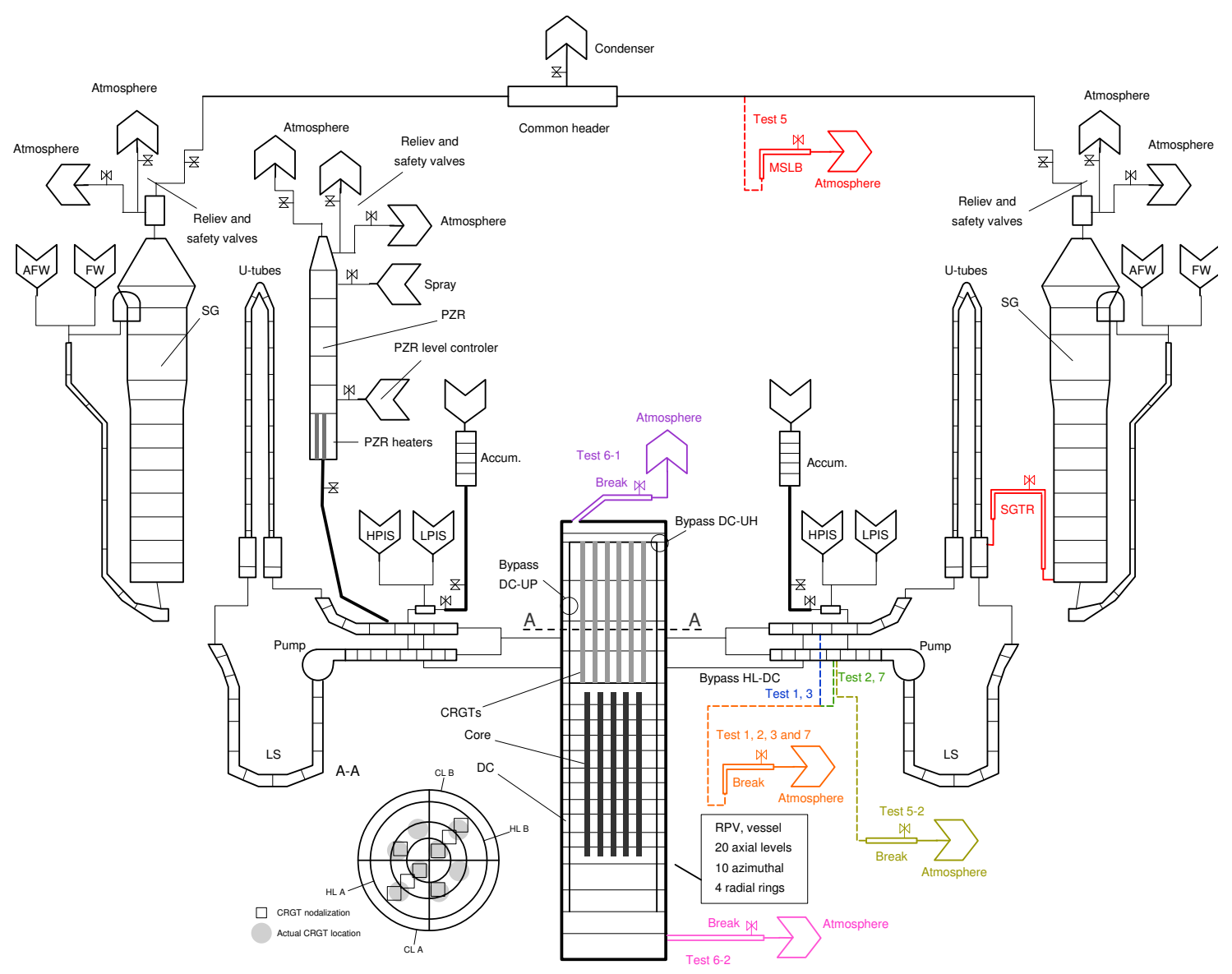

Figure 1: TRACE nodalization of ROSA/LSTF

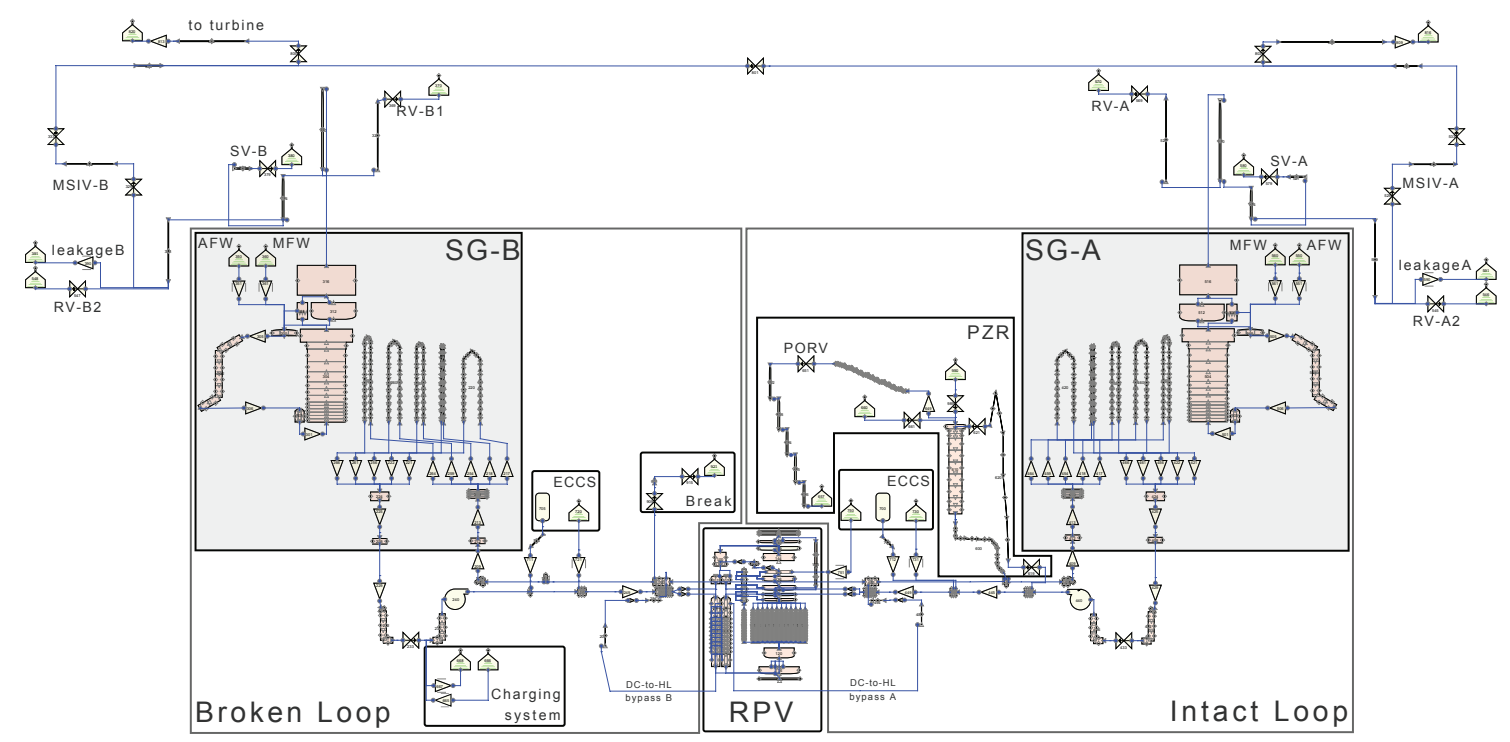

Figure 2: RELAP5 nodalization of ROSA/LSTF 


\begin{tabular}{|c|c|c|c|}
\hline $\begin{array}{l}\text { Facility } \\
\text { Code }\end{array}$ & $\begin{array}{l}\text { ROSA/LSTF } \\
\text { TRACE }\end{array}$ & $\begin{array}{l}\text { ROSA/LSTF } \\
\text { RELAP5 }\end{array}$ & $\begin{array}{c}\text { PKL } \\
\text { RELAP5 }\end{array}$ \\
\hline Choked flow model & $\begin{array}{c}\text { Ransom-Trapp } \\
\text { subcooled coeff. } 1.0 \\
\text { 2-phase coeff. } 0.84\end{array}$ & $\begin{array}{c}\text { Henry-Fauske } \\
\text { discharge coeff. } 0.78 \\
\text { non-equilibrium } 0.14\end{array}$ & $\begin{array}{c}\text { Henry-Fauske } \\
\text { discharge coeff. } 0.78 \\
\text { non-equilibrium } 0.14\end{array}$ \\
\hline Off-take model & $\begin{array}{c}\text { yes } \\
\text { Wallis }\end{array}$ & $\begin{array}{c}\text { yes } \\
\text { Wallis }\end{array}$ & $\begin{array}{c}\text { yes } \\
\text { Wallis }\end{array}$ \\
\hline CCFL UCP & $\begin{array}{c}m=1.0 \\
c=0.8625 \\
\text { Wallis }\end{array}$ & $\begin{array}{c}m=1.0 \\
c=0.8625\end{array}$ & $\begin{array}{c}m=1.0 \\
c=0.8625\end{array}$ \\
\hline SG plena inlet & $\begin{array}{l}m=1.0 \\
c=0.75\end{array}$ & no & no \\
\hline CCFL hot leg & no & $\begin{array}{c}\text { no } \\
\text { Wallis }\end{array}$ & $\begin{array}{c}\text { no } \\
\text { Wallis }\end{array}$ \\
\hline U-tube inlet & no & $\begin{array}{l}m=1.0 \\
c=0.725\end{array}$ & $\begin{array}{l}m=1.0 \\
c=0.725\end{array}$ \\
\hline Reflood model & yes & yes & yes \\
\hline Spacer grid & $\begin{array}{l}\text { represented by k-loss } \\
\text { factors }\end{array}$ & $\begin{array}{c}\text { represented by k-loss } \\
\text { factors and area change }\end{array}$ & $\begin{array}{c}\text { represented by k-loss } \\
\text { factors and area change }\end{array}$ \\
\hline
\end{tabular}

Table 2: Relevant selection of models and settings

\subsection{High pressure transient (ROSA/LSTF)}

The most relevant results of the OECD/NEA ROSA-2 Test 3 are displayed in Figure 3 for the TRACE calculation and in Figure 4 for the RELAP5 calculation. Both figures show the primary and secondary pressures, maximum PCT, break flow and hot leg level and the RPV collapsed water levels.

The results obtained with both codes for the high pressure sequence are in quite close agreement with the experimental data. The primary and secondary pressures follow a similar evolution as in the experiment proving adequate performance of the choked flow in all its phases (subcooled, 2-phase and steam flow).

As can be seen in both figures, the water levels during this phase are well predicted by the two models except for a slightly under-predicted DC level. The reduction of the core level is well predicted and occurs almost at the same time as in the experiment thus allowing for a good prediction of the PCT increase.

Figure 5 shows the evolution of the PCT and the highest CET measurement during the time window when core uncovery takes place. There is a slight time shift of the start of core uncovery although the slope at which the PCT increases is very similar in all cases. There is a clear difference in the delay time between the start of the PCT increase and the CET increase. While the experiment has a time delay of approximately 70 seconds, the delay in the two calculations is of about 30 seconds. Another discrepancy is observed when the core is largely uncovered, in this period the CET temperature in the TRACE calculation increases faster than in the experiment.

\subsection{Low pressure transient (ROSA/LSTF)}

The general trends of the behaviour of the system are also well captured by both models during the low pressure transient of ROSA/LSTF. The RELAP 5 calculation for the low pressure transient presents slightly better results. In the TRACE calculation, the distribution of the coolant in the primary system presents some discrepancies with the experiment. Although the total mass inventory and system pressure are the same at the start of the test, the water level in the DC is lower in the calculation which indicates a slightly 


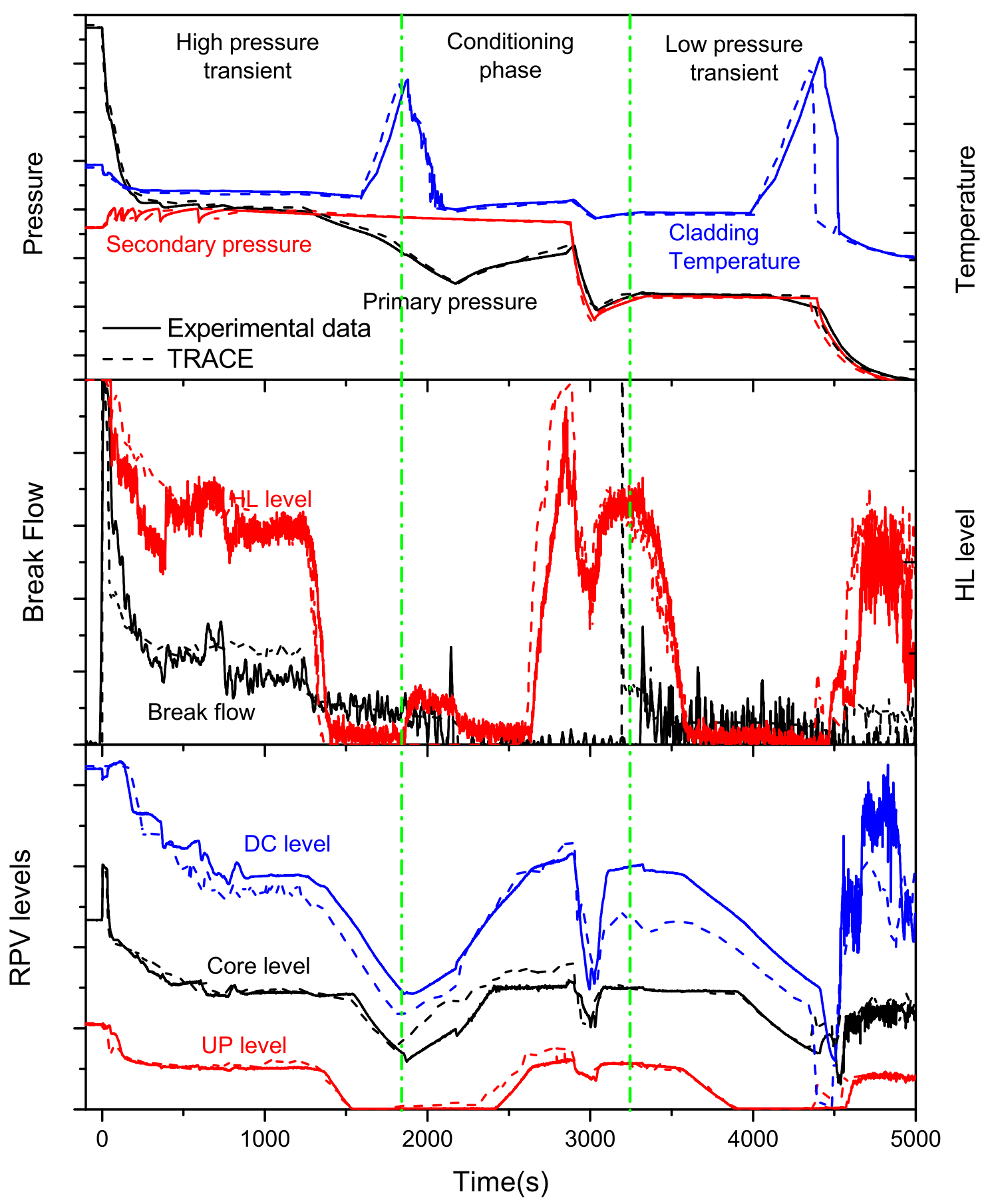

Figure 3: TRACE results for ROSA Test 3. From top to bottom: (1) primary and secondary pressure along with the cladding temperature, (2) break flow and hot leg level close to the break location and (3) RPV collapsed water levels. 


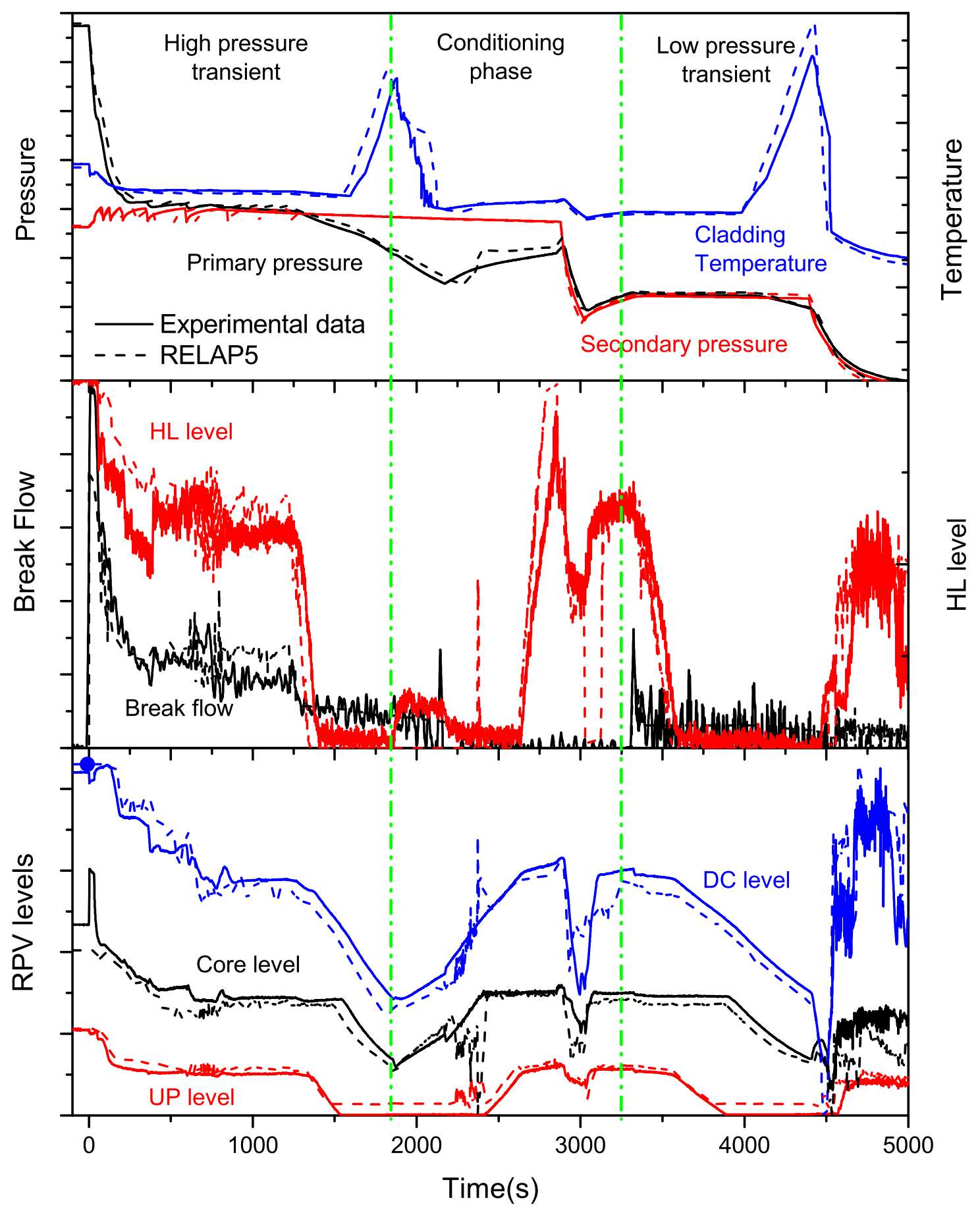

Figure 4: RELAP5 results for ROSA Test 3. From top to bottom: (1) primary and secondary pressure along with the cladding temperature, (2) break flow and hot leg level close to the break location and (3) RPV collapsed water levels. 


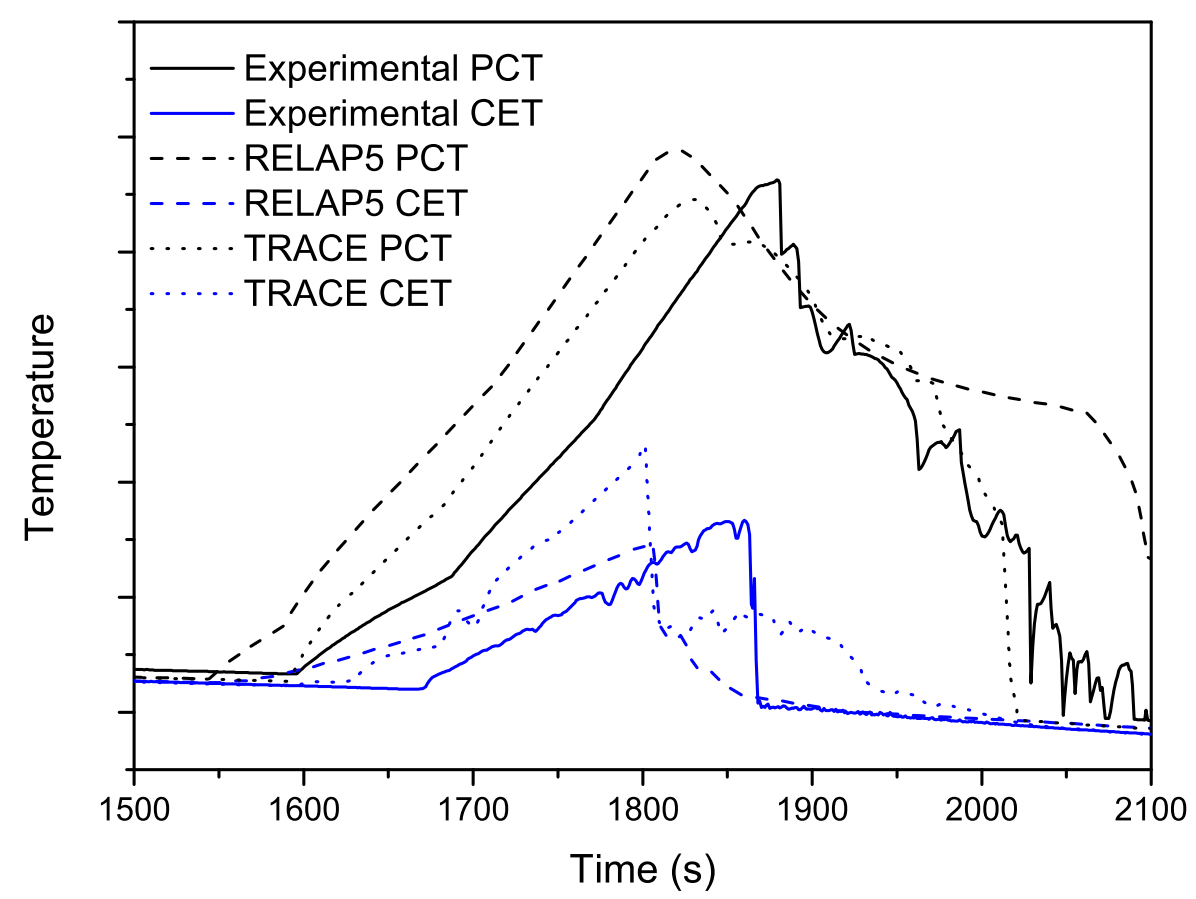

Figure 5: Evolution of the maximum cladding temperature in the core and the CET provided by the TC with the highest values (high pressure transient)

different distribution of coolant in the primary system. In the TRACE calculation, the initial phase (around 3200 s) is characterized by an anticipated and longer duration of the two-phase flow conditions at the break location. As the transient continues, one can observe a rather good simulation of the core and UP levels, whereas the DC mass of coolant is underestimated.

All in all, the results are in quite close agreement with the experiment throughout the whole test permitting an analysis in detail of the CET evolution as function of the PCT.

\subsection{Low pressure transient (PKL)}

The initial conditions in the calculation were achieved in accordance to the experiment. Figure 6 displays the most relevant parameters in terms of system behaviour (primary and secondary pressures, PCT, break mass flow and RPV water levels). The results follow closely the experimental data. Differences are observed after the secondary depressurization is triggered.

In the RELAP5 calculation the depressurization is sufficient to ensure complete reflooding of the core, a result not confirmed by the experiment where accumulator injection was needed in order to achieve this. This difference however does not influence the evolution of the CET and the PCT during core uncovery, which is the main purpose of the present study.

\section{Methodology for the reproduction of the CET}

This section presents the relevant aspects of the modeling approach that were implemented to analyze the physical phenomena that play a significant role in the evolution of the CET as a function of the PCT in the proposed experiments. In addition, the aspects where the code has limitations were identified.

In Section 1.1, the most relevant physical phenomena that the code should be able to represent have been listed. The heat transfer packages of TRACE and RELAP5 have been widely validated with the support of experimental data (The RELAP5 Code Development Team, 2001; United States Nuclear Regulatory 


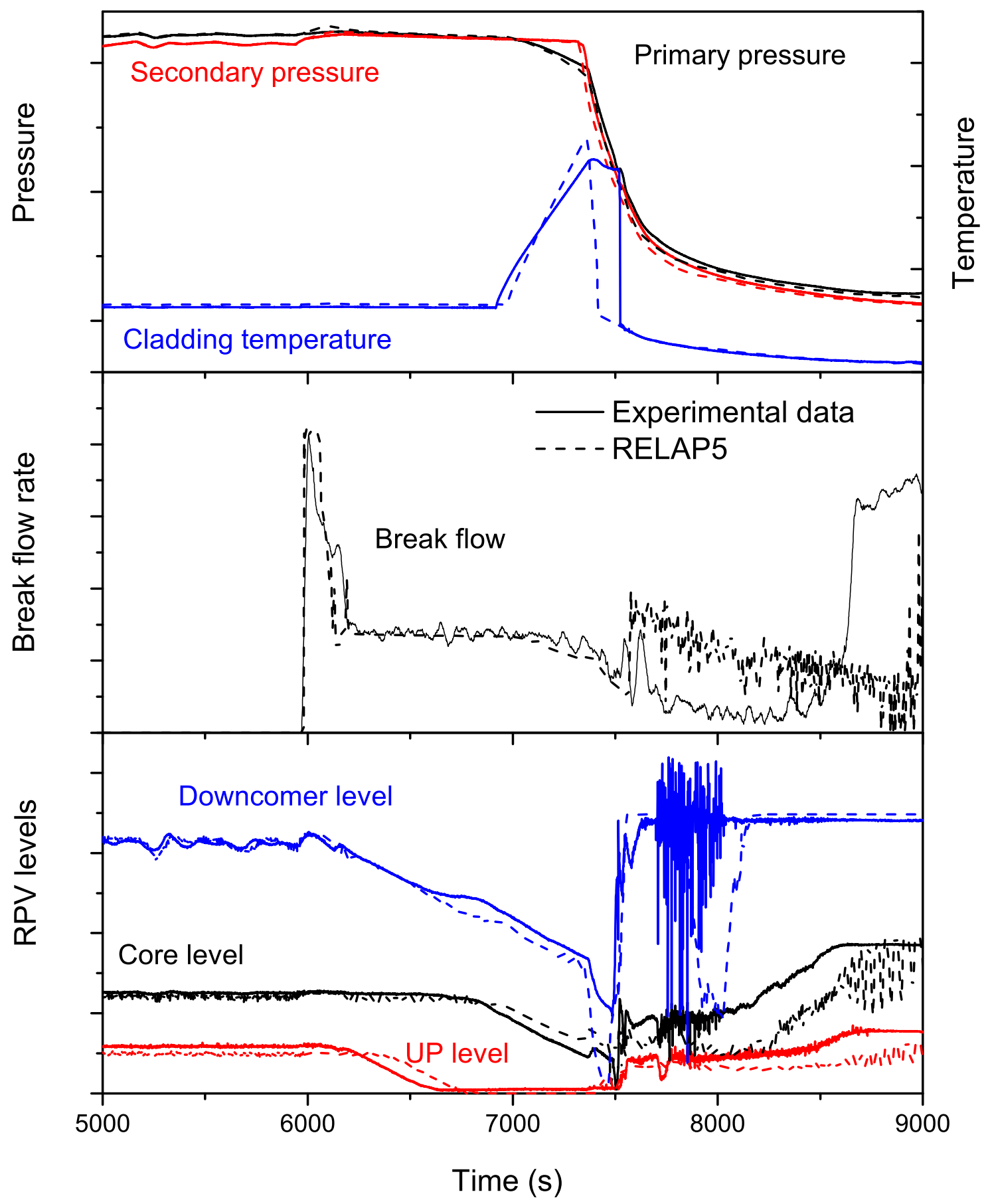

Figure 6: RELAP5 results for PKL Test G7.1. From top to bottom: (1) primary and secondary pressure along with the cladding temperature, (2) break flow and (3) RPV collapsed water levels. 
Commission, 2007; Aksan et al., 1993). Therefore, we can assume that both codes perform sufficiently well to calculate the heat transferred between the fluid and the heat structures (heated and unheated). In this sense, it is not the intention of the authors to address the adequacy of the heat transfer packages of the two codes (to do so, the analysis of separate effect test data would be more indicated). The work is rather focused on how to correctly simulate the complex flow velocity distribution and fluid-structure thermal interactions in the upper part of the core cavity and upstream and around the TCs. This assumption simplifies the problem to the reproduction of four aspects: the correct representation of the heat structures (heated and unheated), the distribution of steam velocities in the region, the fluid mixing in the region, and the water backflow from the hot legs.

Since the PKL Test G7.1 was carried out with flat axial and radial power profiles, the PCT took place at the top of the core and at a rather short distance from the CET location. In addition, the distribution of steam velocities and temperatures were rather homogeneous, therefore most of the following guidelines are primarily related to the ROSA/LSTF pressure vessel nodalization.

\subsection{3-D representation of the core and UP regions and CRGTs}

The steam temperatures and velocities at the core outlet during boil-off will have a heterogeneous radial distribution. This is a consequence of the radial power profiles, the possible liquid flowback from the hot legs and the non-homogeneous size of openings through the core. In order to capture these radial hetereogenities, a $3-\mathrm{D}$ representation of the simulation domain is essential.

In the opinion of the authors, the pseudo 3-D capabilities of current two-phase thermal-hydraulic system codes, based on inviscid flow assumption (except for interactions with wall and phase-interfaces) should be able to capture these details. The hydraulic simulation domain is indeed densely populated with internals (e.g. fuel rods) thus reducing the importance of shear stress in the fluid below the UCP. In the lower part of the UP, local secondary flow patterns should also be outplayed by the pressure gradient induced by the break and the SG heat sink, by the stack effect due to the CRGTs, and by the liquid flowing back from the hot legs. The nodalization must however be sufficiently detailed to take into account the different power zones (or most relevant power zones), possible differences in hole sizes (and shape dependant singular pressure loss coefficients) in the axial planes and non-uniform distribution of passive heat structures. The radial nodalization of the RELAP and TRACE at the UCP elevation for the ROSA/LSTF facility are displayed in Figures 7 and 8, respectively. Each box in the grid represents a vertical pipe which corresponds to the actual geometry. The circles represent the actual openings at the UCP, the areas and hydraulic diameters are calculated according to the correspondent geometry of each cell. As can be seen, the two nodalizations are of comparable refinement and resulted in a more appropriate description of the distribution of holes through the UCP. The openings of the UCP of ROSA/LSTF are very heterougenous in terms of size, and this aspect will have a significant influence in the results. It is important to notice that a typical PWR UCP presents a much more uniform distribution and size of orifices and therefore this effect might be secondary. The same distribution of nodes in the radial plane shown in Figures 7 and 8 is used along the core and UP regions.

\subsection{Heat Structures}

All passive heat structures should be accounted to describe the thermal inertia of this part of the vessel. This includes, unheated fuel rods, support columns, UCP, the endbox and the CRGTs. The cylindrical elements are modeled with a cylindrical geometry were the total volume and the total heat transfer area (HTA) should be preserved. As for the modeling of the UCP, the authors suggest using two distinct heat structures in order to account for the two possible heat transfer directions. The geometry of the UCP is shown in Figure 9. The UCP transfers heat in two directions: axially from the top of the core to the UP and in the radial plane from the holes inner surface to the holes flow path (red lines in Figure 9).

In order to model a passive metal structure in a system code, two important parameters should be adequately described, namely the heat transfer area (HTA) and the total volume of metal. All the hydraulic volume(s) that can exchange heat with the structure should also be defined. To do so, the UCP can be split in two components. In the first component, which captures the heat transfer in the radial direction, the 


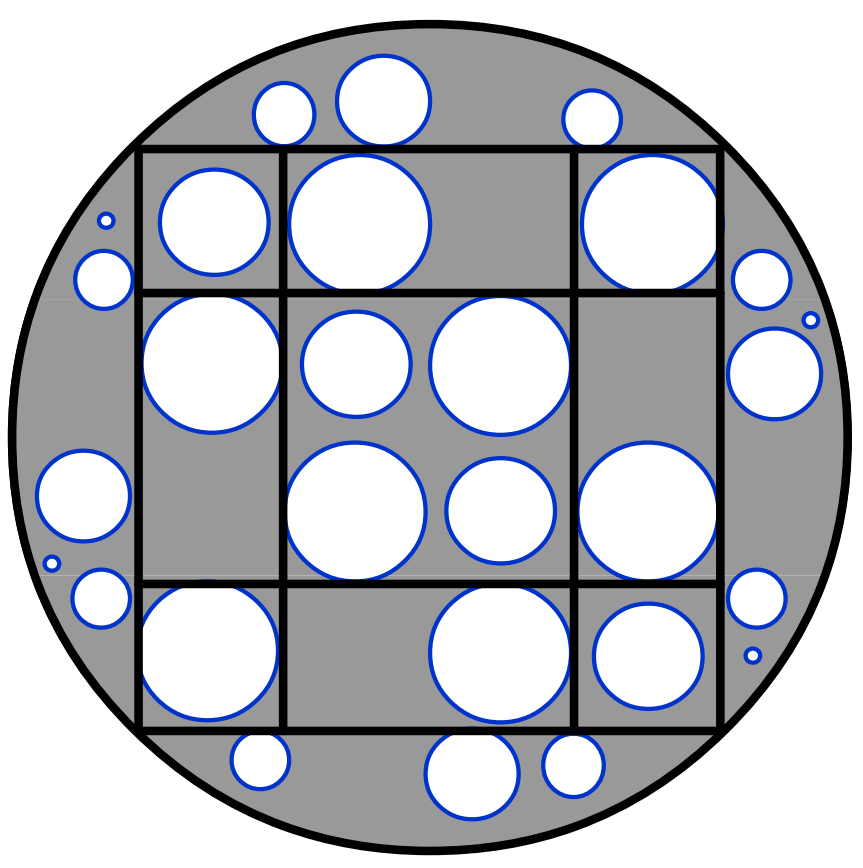

Figure 7: Top view of the UCP in comparison to the radial nodalization of the RELAP model for the core cavity and UP. The circles represent the actual openings at the UCP, the areas and hydraulic diameters in RELAP are calculated according to the correspondent geometry of each cell 


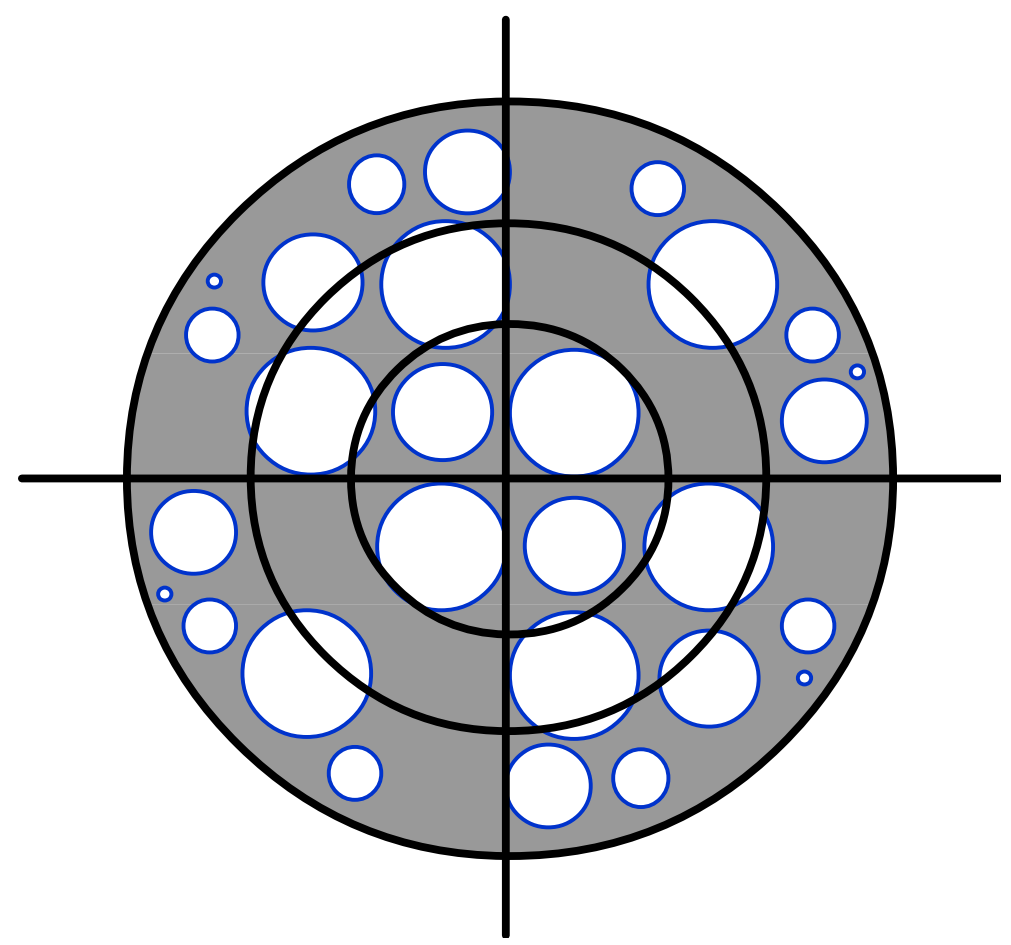

Figure 8: Top view of the UCP in comparison to the radial nodalization of the TRACE model for the core cavity and UP. The circles represent the actual openings at the UCP, the areas and hydraulic diameters in TRACE are calculated according to the correspondent geometry of each cell

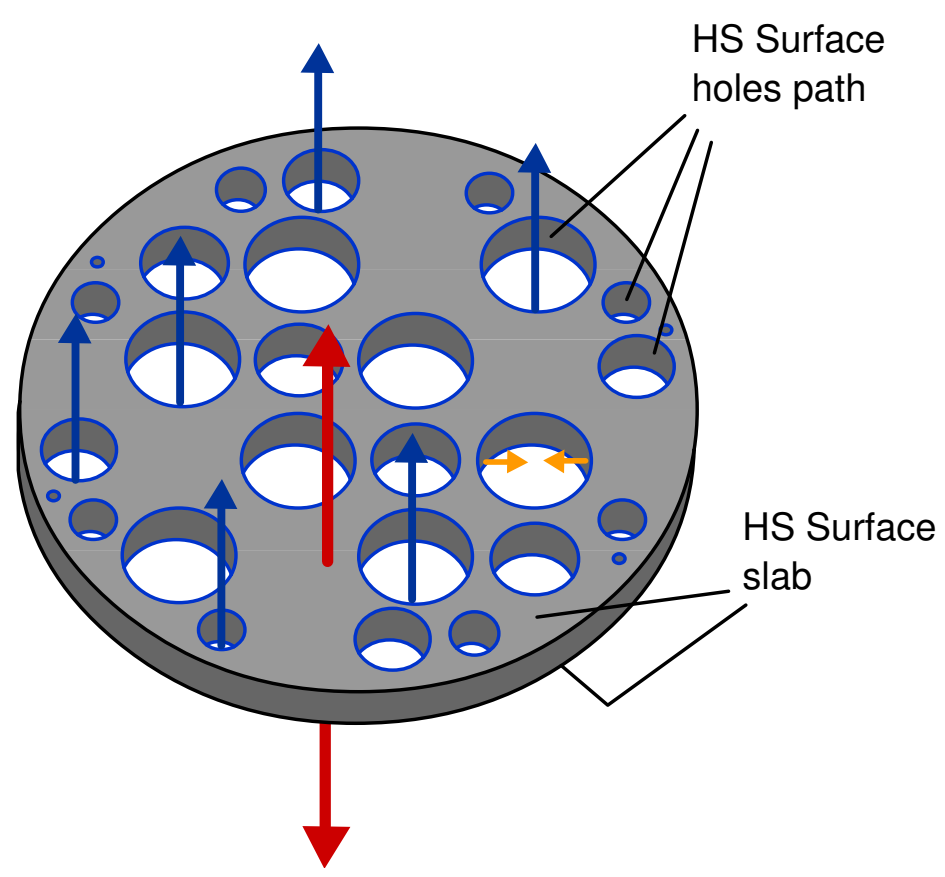

Figure 9: Detail of the upper core plate heat structures 


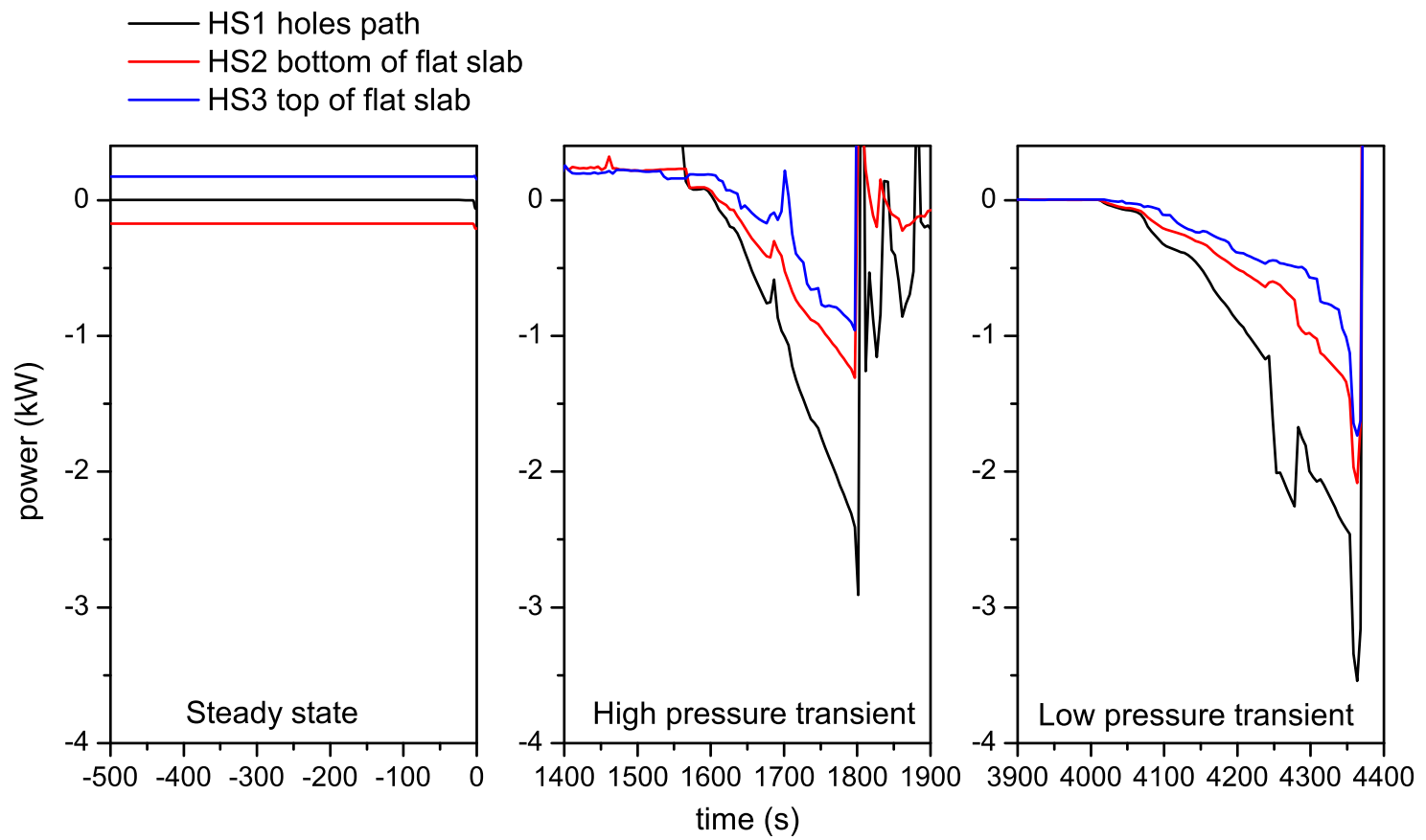

Figure 10: Power transferred from the UCP metal structures to the primary side fluid as calculated by the TRACE code during steady state and the high and low pressure transients of ROSA/LSTF Test 3

HTA of the structure will be equal to the perimeter of the holes multiplied by the thickness of the plate. As for the component describing the heat transfer in the axial direction, the HTA is equal to the area of the slab minus the area of the holes. The structure associated to radial heat transfer is linked to the axial level that represents the UCP thickness (were high fluid velocity are expected), while the flat slab is linked to the axial level above and below the UCP.

In the present study, no heat is exchanged between the two structures and the UCP volume is split proportionally between the two structures according to their respective value of the HTA:

$$
\begin{gathered}
\frac{V_{\text {slab }}}{V_{U C P}}=\frac{H T A_{\text {slab }}}{H T A_{\text {slab }}+H T A_{\text {holes }}} \\
V_{\text {holes }}=V_{U C P}-V_{\text {slab }}
\end{gathered}
$$

Figure 10 displays the power transferred from the two UCP structures to the hydraulic cells in the radial, downward and upward directions for the TRACE calculation of the ROSA-2 Test 3. During steady state, the heat transfer in the holes region is zero because the structure is in thermal equilibrium with the linked hydraulic cell. The bottom and top of the flat slab present positive and negative heat transfer because the fluid in the top of the core is warmer than in the UP. But during the core heat up process of the high and low pressure transients, the heat transfer in the radial direction is higher than in the axial direction, as a consequence of the high steam velocities through the holes. Moreover, the UCP essentially absorbs heat from all sides during the core heat up sequences, thus further dampening the transfer of heat up to the locations of the TC. Therefore, these results emphasize the importance of using a proper nodalization of the UCP in order to correctly capture important local thermal effects influencing the CET responses.

\subsection{Effects of Thermal Radiation}

The RELAP5 code does have a model to simulate thermal radiation effects between heat structures in a defined enclosure. The surfaces that have a line-of-sight or a reflection path through which they can 
communicate with each other can be considered to be in the same enclosure. The computation method used in the RELAP 5 code is a lumped-system approximation for gray diffuse surfaces contained in an enclosure. Basically, the user must define the heat structures that compose the enclosure, the emisivity of each material and the relative view factors. This model is only effective when high temperature differences between surfaces are expected, therefore this will only represent heat tranfer between active and passive heat structures.

The authors of this work considered that this phenomenon will not play a significant role in the evolution of the CET TC mainly because the TC is not in the same enclosure as the fuel rods. In the particular case of LSTF, the following are some additional points that support this statement:

- Radiation intensity from rather low heater rod surface temperature with almost tangential angle to the location of CET TC. The highest temperature portion (max.900 K)

- Influence of radiation absorption by dense steam under high pressure

- The CET measurement is located far from the top end of effective heating range of simulated fuel rods (i. $40 \mathrm{~cm})$

- Obstructing components in between the top end of effective heating and CET TC: 1 spacer grid, the endbox (2 cm thickness) and UCP of $8 \mathrm{~cm}$. A detailed drawing of this region of LSTF can be found in Figure 3.4.2-2 of ref. (Tóth et al., 2010).

- Solid angle from some (not all) of CET TC surface to heater rod surface. Some of TC do not face to heater rod surface. A detailed description of the location of the CET TC in the LSTF can be found in ref. (Suzuki et al., 2009)

- Color (very dark) of oxydized SUS surface through long-term exposure to high temperature water and steam, causing very small light reflection

- Chopped-cosine power profile along the length (height) of the core leads to lower power at the top portion of heater rods. This means that the highest cladding temperature occurs around $2 \mathrm{~m}$ far from the CET TC

\subsection{Steam Velocities}

Another important aspect of the modeling of the CET response is to correctly predict the steam velocities at the core cavity outlet, as this will determine the time of transit from the heated up region to the UP as well as the convective heat transfer coefficient between the steam flow and the UCP. To do so, the exact geometry of the holes should be described. Figures 7 and 8 display the distribution and size of holes of the UCP, together with the radial distribution of the cells in the TRACE and RELAP5 nodalizations for the core and UCP regions. One can notice that some radial sectors include very large holes, while in other sectors the flow is nearly blocked by the UCP. The nodalization of the UCP openings was modified accordingly. As shown in Figure 8 in the TRACE nodalization two zones have nearly no openings, these two connections were nodalized with a null area.

The steam velocities will additionally be affected by the location and openings of the CRGTs because the direct connection to the rather cold and stagnant flow conditions in the UH might accelerate the flow in certain locations (stack effect).

\subsection{Fluid Mixing}

Fluid mixing in the region between the quench front and the CET location will have an impact on the final steam temperatures detected by the CET measurement. This region will be filled mainly by pure steam.

The fluid mixing in this area will be primarily driven by the axial and radial pressure gradients, which will in turn be governed by the core power distribution, the geometrical details and the viscous stresses. As discussed in Section 4.1, despite the known limitations of system codes with respect to the simulation of complex 3-D flow configurations, the expected flow configuration in this region of the vessel should be captured relatively well, through careful modeling of the geometry and power distribution. 


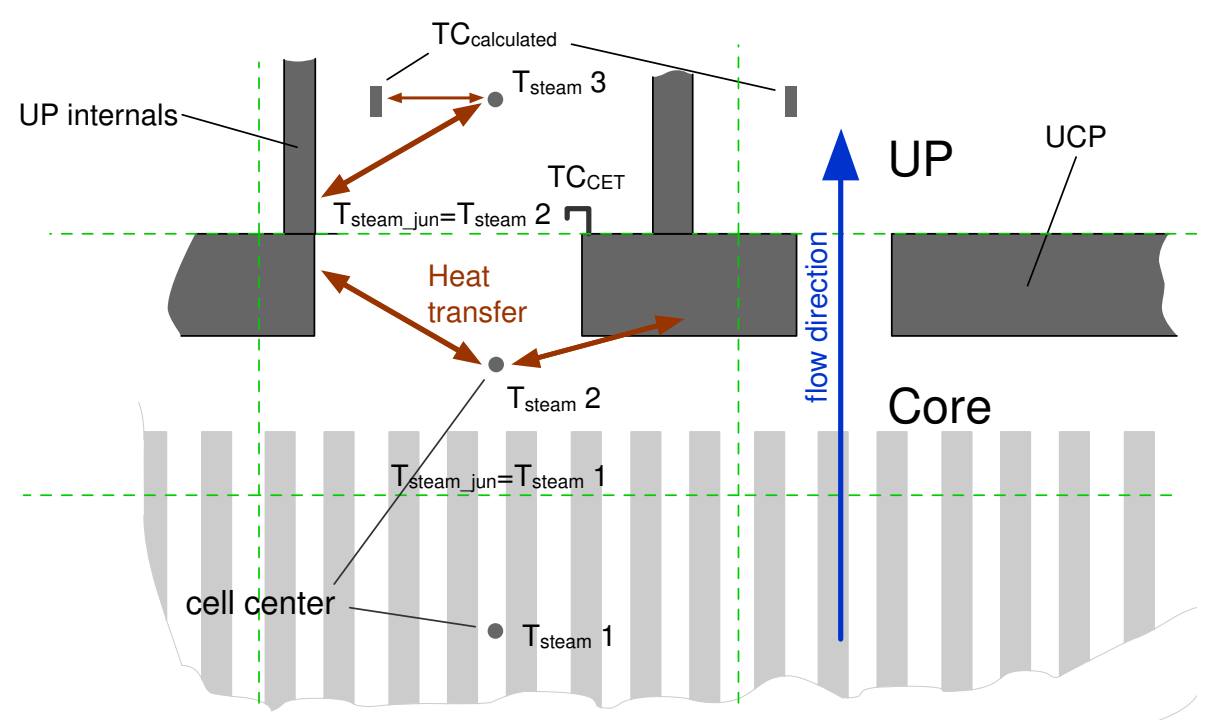

Figure 11: Detail of the location of the CET in comparison to the calculated CET

\subsection{Water Backflow and location of the CET measurement}

Adams and Mccreery (1983) pointed out that during experiments at the LOFT facility, slow drainage of liquid from the upper plenum coated the core exit TCs with a liquid film during core uncovery. Adams and Mccreery (1983) mentioned that for a CET TC to respond to an inadequate core cooling condition, this film had to be removed by one or more of the following mechanisms: additional heat flux to boil it off, primary system depressurization to flash the film to vapor, or sufficient steam velocity to strip it off. Finally, it was stated that only when this film was removed the CET TC were equal to the vapor temperatures at the core exit. Often, the CET evolution is represented in system codes by plotting the steam temperature, a readily available variable in the system codes. According to these findings, this assumption will not be correct when liquid is present in the vicinity of the TC.

In the present study, instead of considering the steam temperature variable, the CET temperature has been obtained by simulating the TC explicitly. Thus, considering that the TC should be in thermal equilibrium with the outer wall of the sensor itself, therefore, one can simulate the TC by adding a heat structure having the size and the thermophysical properties of a thermocouple. Such heat structure has been included in each core exit node. The wall surface temperature of this heat structure is used as CET reading instead of the steam temperature. A detail of the nodalization of this region is provided in Figure 11.

\section{Results}

Maximum cladding temperatures as function of the CET measurements for the two transient sequences of the ROSA-2 Test 3 (the high and low pressure events) are shown in Figures 12, 13, 14 and 15. The black circles show the experimental values obtained at the CET thermocouple that reported the highest temperatures, and the black squares display the CET TC that showed the lowest temperatures. The TC temperatures calculated in all the nodes just above the UCP are plotted in red. We can observe that the CET(PCT) evolution is strongly dependent on the planar location. The 3-D approach was useful to reproduce a spread of temperatures above the core.

One can observe that initially the curves depart from the equilibrium condition ( $\mathrm{PCT}=\mathrm{CET}$ ) with a nearly vertical slope. This represents the initial phase of the core uncovery and indicates an increase of the PCT while the steam temperatures above the core remain at saturation conditions. During this phase the 


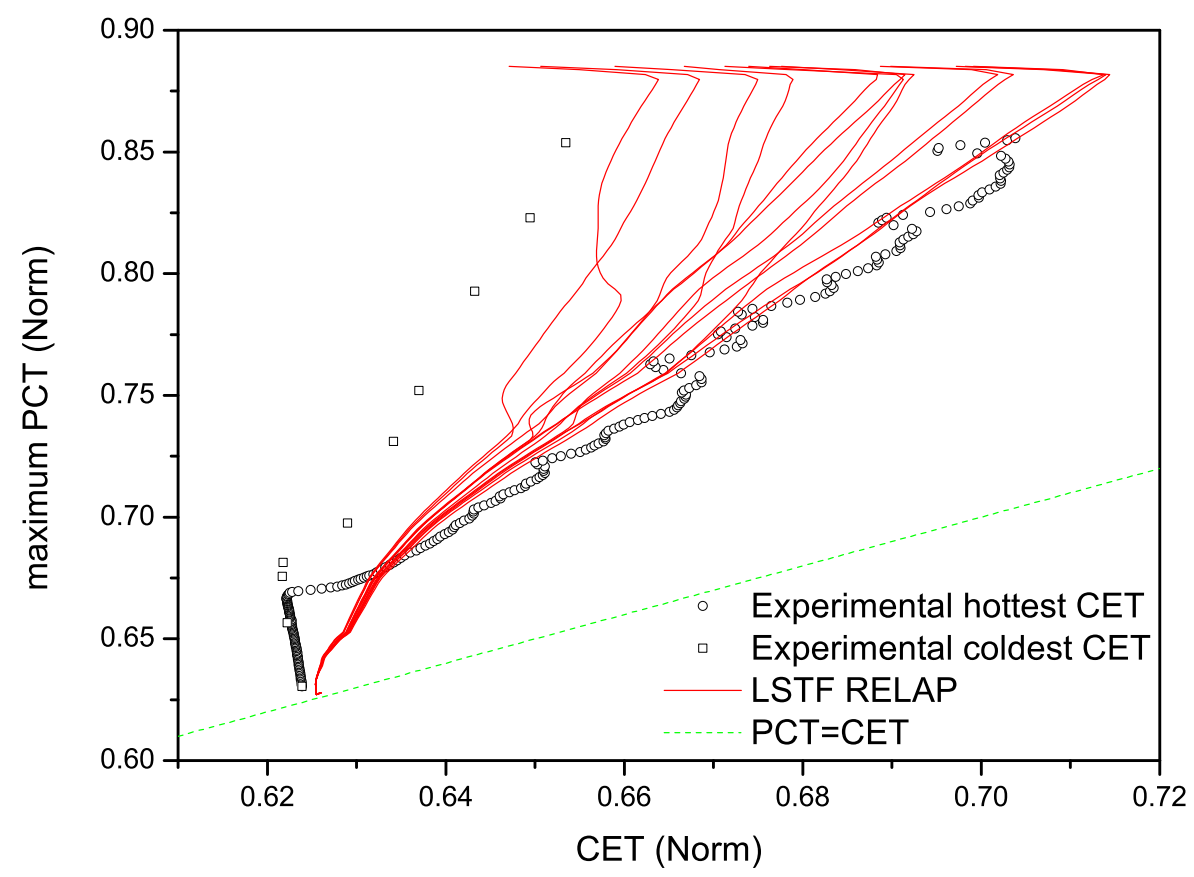

Figure 12: Maximum cladding temperature as function of the CET for the high pressure transient of ROSA-2 Test 3 in comparison to the RELAP5 results. Each red line corresponds to the different computational cells available at the UCP location

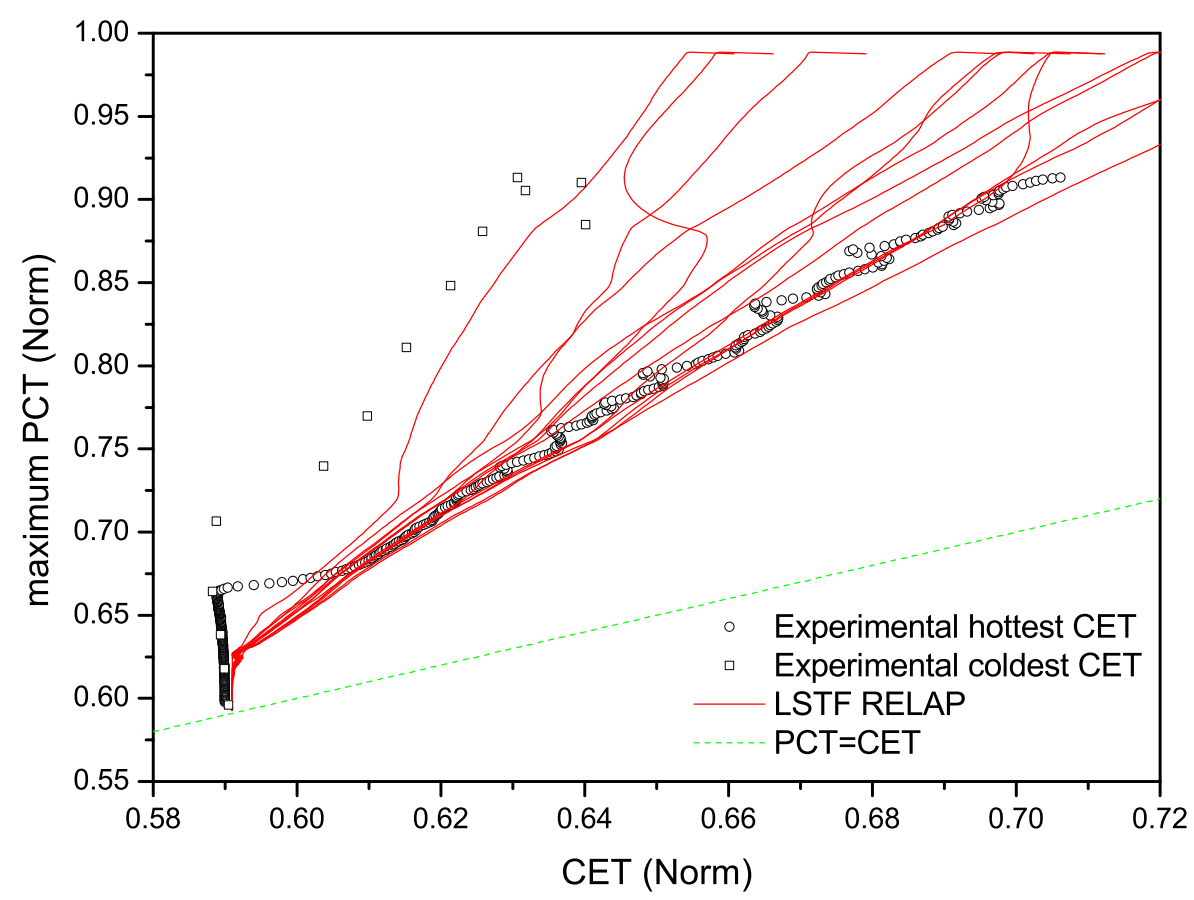

Figure 13: Maximum cladding temperature as function of the CET for the low pressure transient of ROSA-2 Test 3 in comparison to the RELAP5 results. Each red line corresponds to the different computational cells available at the UCP location 


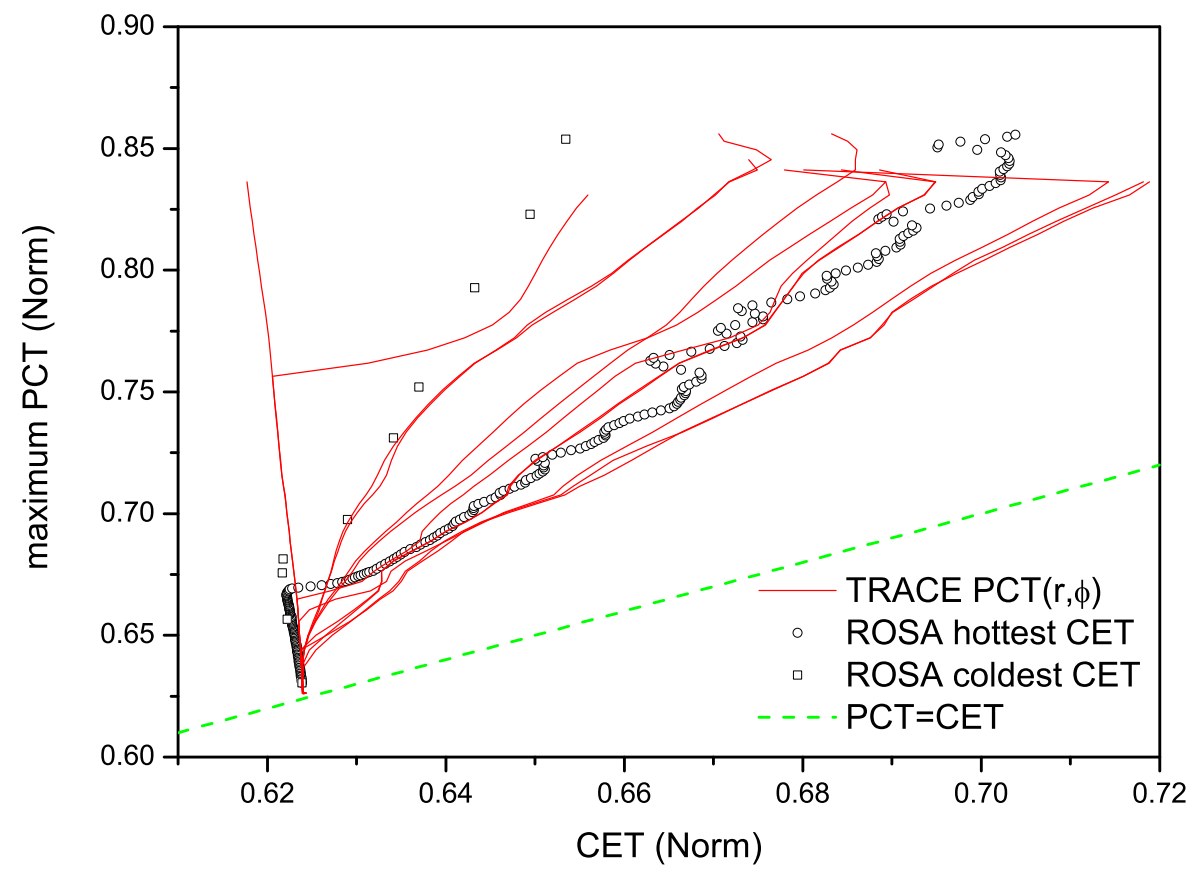

Figure 14: Maximum cladding temperature as function of the CET for the high pressure transient of ROSA-2 Test 3 in comparison to the TRACE results. Each red line corresponds to the different computational cells available at the UCP location

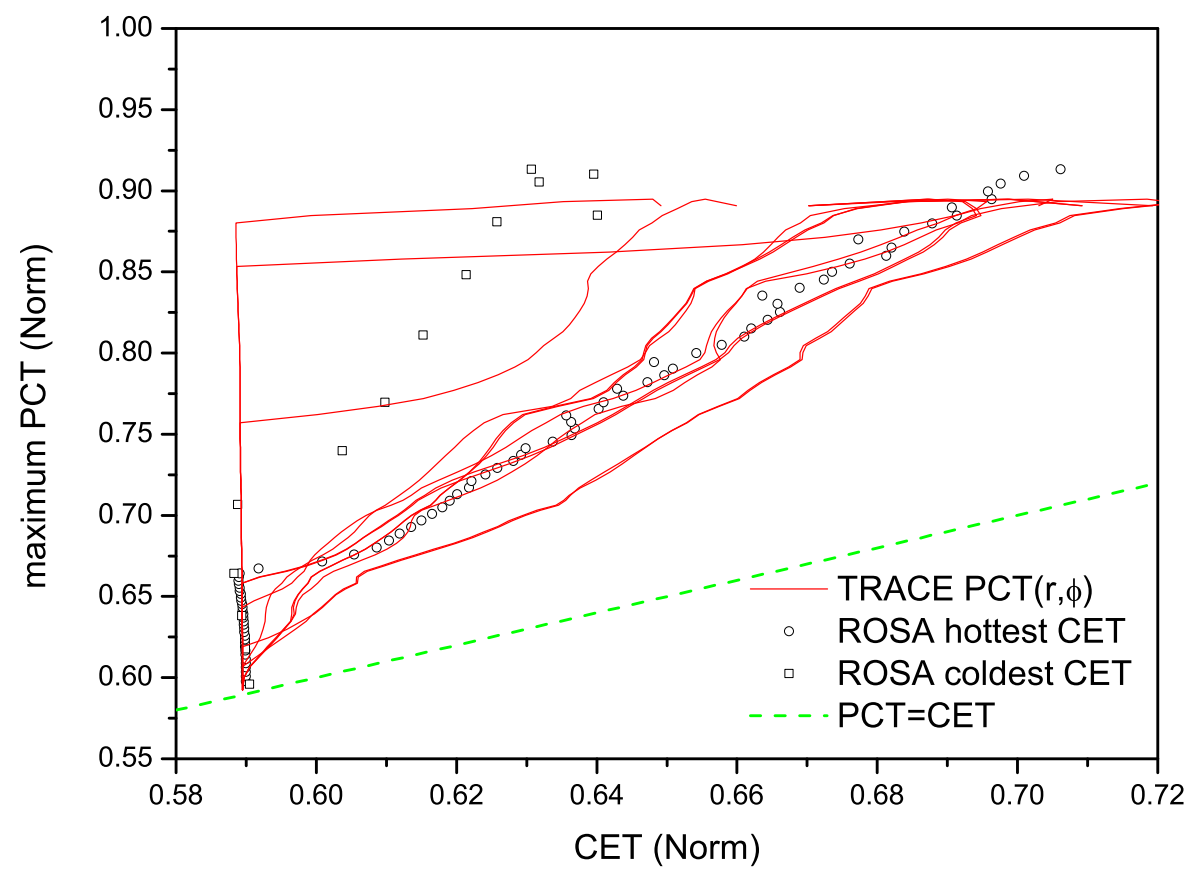

Figure 15: Maximum cladding temperature as function of the CET for the low pressure transient of ROSA-2 Test 3 in comparison to the TRACE results. Each red line corresponds to the different computational cells available at the UCP location 
operators would not see any indication (steam superheating) of the initiation of a core heat up. Indeed, the superheated steam may be fully cooled by the passive heat structures before reaching the CET TC. Another phenomenon that induces this initial vertical increase is the one related to the experimental observations given by Adams and Mccreery (1983) who indicated that a film of liquid water forms around the TC and superheating will not be detected until the film dries out. It can be seen that this initial vertical slope is much longer in the experiment than in the calculations. The vertical lines in the RELAP5 calculations does not depend on the location, as opposed to the TRACE calculation where the departure from the vertical line is strongly dependent on the radial and azimuthal location.

After this initial increase, the curve slope of the PCT as a function of the hottest CET is similar in all cases. Some of the TRACE curves are below the experimental data showing a slight overprediction of the CET value and therefore would provide anticipated AM measures. The variability in the CET responses as function of the radial location is also indicative of the importance of the selection of the locations of the CET sensors with respect to the EOP.

Regarding the evolution of the cold CET spots, one can find similarities between the experimental and the calculated values although the results are highly affected by uncertainties. The higher upward vertical flow should take place in the zone with higher power whereas lower, colder (possibly downward) steam flows may take place in the peripherical low power zones. As discussed in Section 4.1, system codes are not well equipped to predict such complex 3-D flow patterns. Therefore, as observed in Figures 12, 13, 14 and 15, larger discrepancies between calculation results and experiment are to be expected in the low power low flow zones of the UCP.

It is important to highlight that some CET results obtained by TRACE kept unresponsive to the PCT, thus indicating that the corresponding TC did not detect any superheated steam (vertical red lines in Figures 14 and 15). A plausible explanation is that sufficient liquid remained in the corresponding hydraulic cells to keep the TC heat structures wetted. The void fraction distribution in the UP as obtained by TRACE and RELAP5 for the high pressure transient are shown in Figure 16. Indeed, two cells above the core in the TRACE nodalization remained with a considerable fraction of liquid, this two cells correspond to the cells that are not directly connected to the core cavity below, representing the regions of the UCP with no openings (see Figure 8 and Section 4.4). At these locations, the simulation of dedicated heat structures to model the TC response is essential. Figure 17 compares steam temperatures and surface temperatures of the corresponding TC heat structures in different locations right above the UCP. The black and red curves correspond to the locations with zero opening to the core cavity. In these hydraulic cells the steam and surface temperatures present very different behaviours. Since a small amount of liquid remains in the cell which can neither be vaporised by upward flowing superheated steam from the core nor can flow down in the core cavity, the code estimates it to form a thin layer around the heat structures Therefore the steam in the cell is superheated while the surface temperature is at saturation conditions. The blue and green curves in the bottom graph of Figure 17 correspond to locations where the cell has been completely dried out and in these cases the surface and steam temperatures are almost equal. This results show that system codes, provided with adequate nodalization, are able to reproduce the experimental observations pointed out by Adams and Mccreery (1983).

Figure 18 shows the maximum cladding temperatures as a function of the CET for the PKL Test G7.1. The calculated results are in close agreement with the experimental data. The initial vertical increase is well reproduced and the slope that follows is also in accordance to the experiment results. As can be seen, both the experiment and the calculation provided homogenous results at the core exit. This result is not surprising due to the elongated shape of the pressure vessel of the PKL facility, combined with the homogeneous perforation of the UCP (one opening per fuel rod simulator) and the uniform axial and radial power distribution employd for the Test G7.1.In this sense, the study of Test G7.1 further confirms the soundness and applicability of the nodalization principles to more homogeneous geometries and core power distributions. 


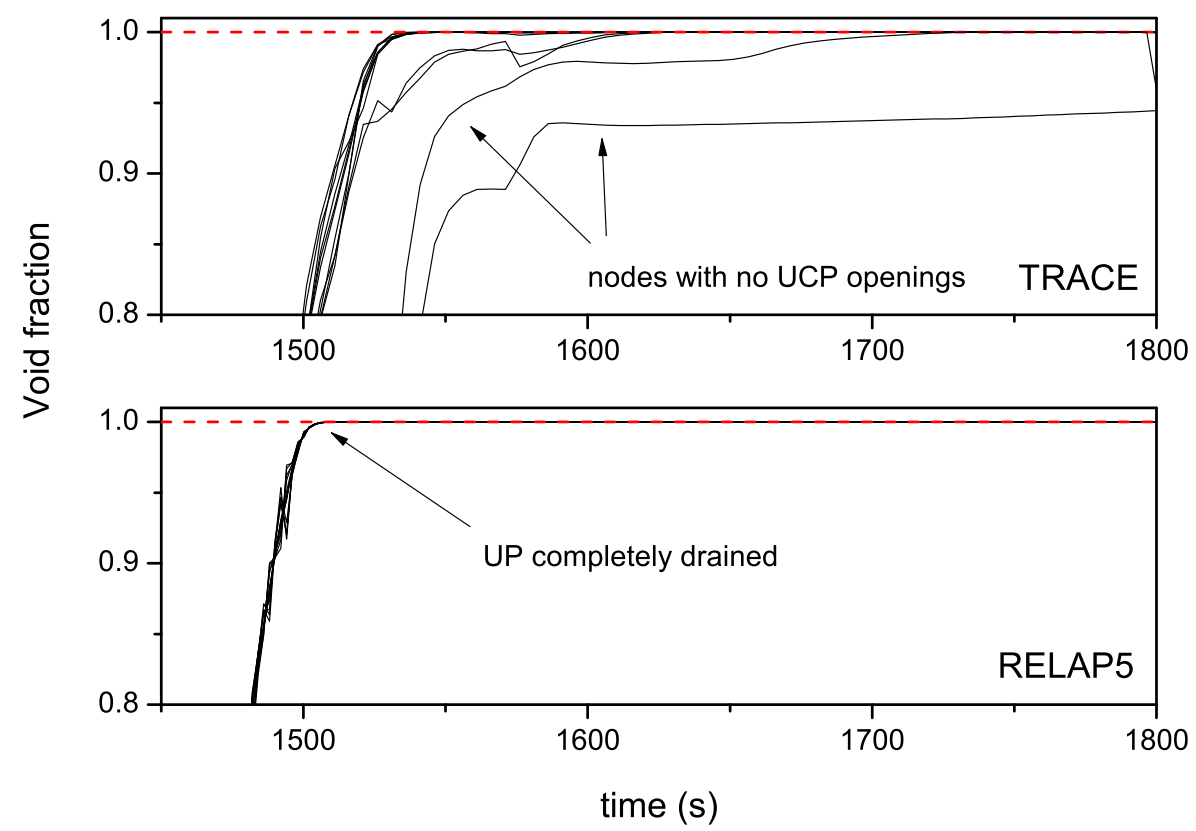

Figure 16: fraction occupied by steam in the UP during the high pressure phase core uncovery. TRACE results are shown in the top graph, RELAP5 results in the bottom graph

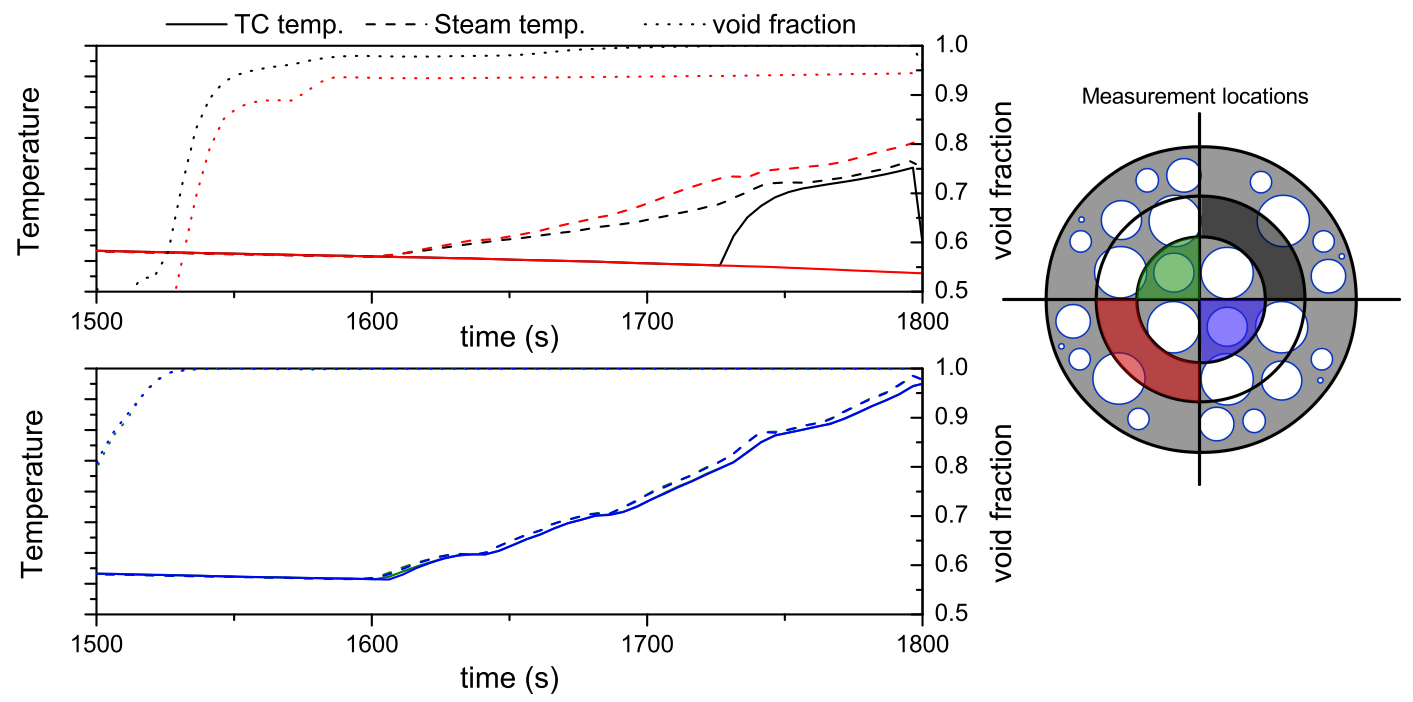

Figure 17: Steam temperatures anc TC temperatures calculated by TRACE during the high pressure transient of LSTF Test 3 


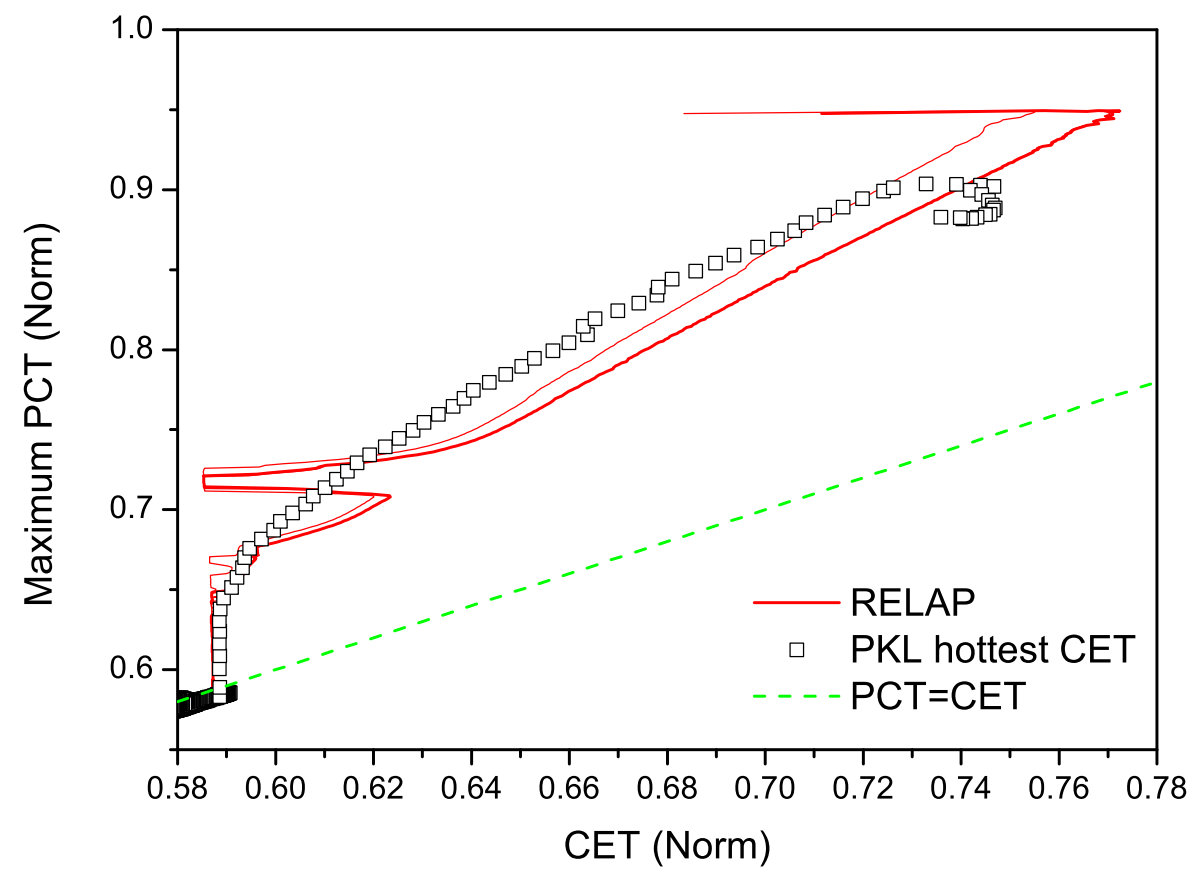

Figure 18: Maximum cladding temperature as function of the CET for the low pressure transient of PKL Test G7.1 in comparison to the RELAP5 results. Each red line corresponds to the different computational cells available at the UCP location 


\section{Conclusions}

Two experiments, Test 3 of the OECD/NEA ROSA-2 and Test G7.1 of the OECD/NEA PKL-2 projects, composing the counterpart exercise have been simulated by making use of the RELAP 5 and TRACE system codes. The main objective of the counterpart experiments and simulations was to analyze the performance of the CET measurements during a core heat up scenario following an SBLOCA event. The nodalizations were able to reproduce generally well the system behaviour of the two ITFs and thus were suitable for a more detailed analysis of the relation between the CET and the PCT.

Following recommendations from Tóth et al. (2010), the simulations have been carried out with the intention of defining a methodology to correctly reproduce the performance of the TCs located at the core exit. The important physical phenomenology that the code should reproduce have been identified and general guidelines on how to reproduce them with current system codes have been proposed. Three main aspects were identified to be crucial to correctly model the CET temperature: (1) a detailed modelling of the passive heat structures in the core and UP regions, (2) an accurate modelling of the geometrical aspects of the core and UP regions including the CRGTs and (3) the simulation of the TCs by using dedicated heat structures instead of the usage of the default steam temperatures provided by the code. When adopting these principles, a 3-D representation of the region could provide a good account of the heterogeneous conditions in the region. In this sense, both RELAP and TRACE system codes showed to be suitable to analyze the CET-PCT issue.

The employed nodalization methodology produced heterogeneous results at the core exit in the same manner as in the experiments. Uncertainties were seen to be specially high for the core exit zones that reported lower temperatures. This promising results call for further assessment studies, possibly including BEPU methods in order to better dissociate the nodalization effects discussed in this work, from the other potential sources of uncertainties in the models.

\section{Acknowledgements}

The present work contains findings that were produced within the OECD/NEA ROSA-2 and OECD/NEA PKL-2 projects. The authors are grateful to the Management Board of both projects for their consent to this publication. The authors also want to thank the Spanish Safety Council (CSN) and the Swiss Federal Nuclear Safety Inspectorate ENSI (Eidgenössisches Nuklearsicherheitsinspektorat) that have partially funded this research.

\section{References}

Adams, J. P., Mccreery, G. E., 1983. DETECTION OF INADEQUATE CORE COOLING WITH CORE EXIT THERMOCOUPLES : LOFT PWR EXPERIENCE. Tech. Rep. NUREG/CR-3386, USNRC. URL http://pbadupws.nrc.gov/docs/ML1303/ML13032A566.pdf

Aksan, N., d'Auria, F., Glaeser, H., Pochard, R., Richards, C., Sjoberg, A., July 1993. Separate Effects Test Matrix for thermalhydraulic code validation. Tech. Rep. NEA/CSNI/R(93)14, Committee on the Safety of Nuclear Installations, OECD, Nuclear Energy Agency.

Freixa, J., Kim, T.-W., Manera, A., 2013a. Post-test thermal-hydraulic analysis of two intermediate $\{$ LOCA $\}$ tests at the \{ROSA\} facility including uncertainty evaluation. Nuclear Engineering and Design 264 (0), 153 - 160, sI:NURETH-14.

Freixa, J., Manera, A., 2010. Analysis of an RPV upper head SBLOCA at the ROSA facility using TRACE. Nuclear Engineering and Design 240 (7), $1779-1788$

Freixa, J., Manera, A., 2012. Remarks on Consistent Development of Plant Nodalizations: An Example of Application to the ROSA Integral Test Facility. Science and Technology of Nuclear Installations 2012 (Article ID 158617). URL http://dx.doi.org/10.1155/2012/158617

Freixa, J., Reventós, F., Pretel, C., Batet, L., Sol, I., 2009. SBLOCA with boron dilution in pressurized water reactors. Impact on operation and safety. Nuclear Engineering and Design 239 (4), $749-760$.

Freixa, J., Zerkak, O., Belaid, S., 2013b. Thermal-hydraulic system code performance for SBLOCA phenomenology under different geometries and scales. In: NURETH-15.

Kremin, H., limprecht, H., Güneysu, R., Umminger, K., july 2001. Description of the PKL III Test Facility. Tech. rep., Framatome ANP report.

Martinez-Quiroga, V., Reventos, F., 2014. The Use of System Codes in Scaling Studies: Relevant Techniques for Qualifying NPP Nodalizations for Particular Scenarios. Science and Technology of Nuclear Installations 2014, 1-13. URL http://www.hindawi.com/journals/stni/2014/138745/ 
Martinez-Quiroga, V., Reventos, F., Freixa, J., 2014. Applying UPC Scaling-Up Methodology to the LSTF-PKL Counterpart Test. Science and Technology of Nuclear Installations 2014, 1-18.

URL http://www.hindawi.com/journals/stni/2014/292916/

Martinez-Quiroga, V., Reventos, F., Pretel, C., 2012a. Post-Test Calculation of the ROSA/LSTF Test 3-1 Using RELAP5/Mod3.3. Tech. Rep. NUREG/IA-409, USNRC.

URL http://pbadupws.nrc.gov/docs/ML1208/ML12083A011.pdf

Martinez-Quiroga, V., Reventos, F., Pretel, C., Lstf, R., Using, T., Mod, R., 2012b. Post-Test Calculation of the ROSA/LSTF Test 3-2 Using RELAP5/Mod3.3. Tech. Rep. NUREG/IA-0410, USNRC.

URL http://pbadupws.nrc.gov/docs/ML1208/ML12083A012.pdf

Schoen, B., Schollengerger, S. P., Umminger, K., 2012. Test PKL III G7.1: SBLOCA with total failure of HPSI (Counterpart Testing with ROSA/LSTF) - Quick Look Report. Tech. Rep. PTCTP-G/2011/en/0008, Areva.

Suzuki, M., Takeda, T., Nakamura, H., 2009. Performance of core exit thermocouple for pwr accident management action in vessel top break loca simulation experiment at oecd/nea rosa project. Journal of Power and Energy Systems 3 (1), $146-157$.

Takeda, T., Nakamura, H., Suzuki, M., 2007. OECD / NEA ROSA Project Experimental Data / Information Transfer Performance of Core Exit Temperatures for Accident Management Action in LSTF 1.9\% Top Break LOCA Test ( Supplemental Report for Test 6-1 ). Tech. rep., Japan Atomic Energy Agency.

Takeda, T., Suzuki, M., Asaka, H., Nakamura, H., 2006. Quick-look Data Report of OECD/NEA ROSA Project Test 6-1 (1.9\% Pressure Vessel Upper-head Small Break LOCA Experiment). Tech. Rep. JAEA-Research 2006-9001, Japan Atomic Energy Agency.

Takeda, T., Suzuki, M., Asaka, H., Nakamura, H., 2012. Quick-look Data Report of ROSA-2/LSTF Test 3 (Counterpart Test to PKL SB-HL-18 in JAEA). Tech. Rep. JAEA-Research 2012-, Japan Atomic Energy Agency.

The RELAP5 Code Development Team, 2001. Relap5/Mod3.3 Code Manual. Volume VI: Validation of Numerical Techniques in RELAP5/MOD3.0.

The ROSA-V Group, 2003. ROSA-V Large Scale test facility (LSTF) system description for the third and fourth simulated fuel assemblies. Tech. Rep. JAERI-Tech 2003-037, Japan Atomic Energy Agency.

Tóth, I., Prior, R., Sandervag, O., Umminger, K., Nakamura, H., Muellner, N., Cherubini, M., Del Nevo, A., D'Auria, F., Dreier, J., Alonso, J. R., Amri, A., October 2010. Core exit temperature (CET) effectiveness in accident management of nuclear power reactors. Tech. Rep. NEA/CSNI/R(2010)9, Committee on the Safety of Nuclear Installations, OECD, Nuclear Energy Agency.

United States Nuclear Regulatory Commission, 2007. TRACE v5.0 Theory Manual, Field Equations, Solution Methods, and Physical Models. 